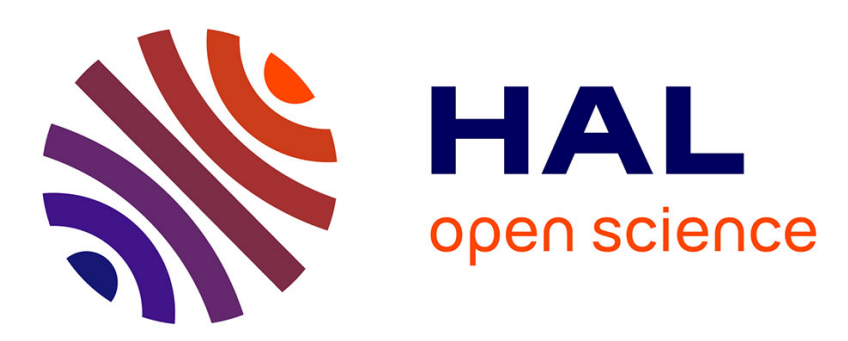

\title{
African monsoon teleconnections with tropical SSTs: Validation and evolution in a set of IPCC4 simulations
}

Mathieu Joly, Aurore Voldoire, Hervé Douville, Pascal Terray, Jean-François Royer

\section{- To cite this version:}

Mathieu Joly, Aurore Voldoire, Hervé Douville, Pascal Terray, Jean-François Royer. African monsoon teleconnections with tropical SSTs: Validation and evolution in a set of IPCC4 simulations. Climate Dynamics, 2007, 29 (1), pp.1-20. 10.1007/s00382-006-0215-8 . meteo-00996738

\section{HAL Id: meteo-00996738}

\section{https://hal-meteofrance.archives-ouvertes.fr/meteo-00996738}

Submitted on 26 May 2014

HAL is a multi-disciplinary open access archive for the deposit and dissemination of scientific research documents, whether they are published or not. The documents may come from teaching and research institutions in France or abroad, or from public or private research centers.
L'archive ouverte pluridisciplinaire HAL, est destinée au dépôt et à la diffusion de documents scientifiques de niveau recherche, publiés ou non, émanant des établissements d'enseignement et de recherche français ou étrangers, des laboratoires publics ou privés. 


\title{
African monsoon teleconnections with tropical SSTs: Validation and evolution in a set of IPCC4 simulations
}

\author{
Mathieu Joly ${ }^{1}$ \\ Aurore Voldoire ${ }^{1}$ \\ Hervé Douville $^{1}$ \\ Pascal Terray $^{2}$ \\ Jean-François Royer ${ }^{1}$ \\ ${ }^{1}$ Météo-France, Toulouse, France \\ ${ }^{2}$ IPSL, Paris, France \\ Climate Dynamics
}

Submission: 24 March 2006

Revision: 18 July 2006

Corresponding author address:

Mathieu JOLY

Météo-France, CNRM/GMGEC/UDC

42 avenue $\mathrm{G}$. Coriolis

31057 TOULOUSE cedex 1, France

E-mail: mathieu.joly@meteo.fr

Tel: (+33) 561079832 - Fax: (+33) 561079610 


\section{Abstract}

A set of twelve state-of-the-art coupled ocean-atmosphere General Circulation Models (OAGCMs) is explored to assess their ability to simulate the main teleconnections between the West African monsoon (WAM) and the tropical sea surface temperatures (SSTs) at the interannual to multi-decadal time scales. Such teleconnections are indeed responsible for the main modes of precipitation variability observed over West Africa and represent an interesting benchmark for the models that have contributed to the $4^{\text {th }}$ Assessment Report of the Intergovernmental Panel on Climate Change (IPCC4). The evaluation is based on a Maximum Covariance Analysis (MCA) applied on tropical SSTs and WAM rainfall. To distinguish between interannual and multi-decadal variability, all datasets are partitioned into LowFrequency (LF) and High-Frequency (HF) components prior to analysis.

First applied to HF observations, the MCA reveals two major teleconnections. The first mode highlights the strong influence of the El Niño Southern Oscillation (ENSO). The second mode reveals a relationship between the SST in the Gulf of Guinea and the northward migration of the monsoon rainbelt over the West African continent. When applied to HF outputs of the $20^{\text {th }}$ century IPCC4 simulations, the MCA provides heterogeneous results. Most simulations show a single dominant Pacific teleconnection, which is however of the wrong sign for half of the models. Only one model shows a significant second mode, emphasizing the OAGCMs' difficulty in simulating the response of the African rainbelt to Atlantic SST anomalies that are not synchronous with Pacific anomalies.

The LF modulation of these HF teleconnections is then explored through running correlations between Expansion Coefficients (ECs) for SSTs and precipitation. The observed time series indicate that both Pacific and Atlantic teleconnections get stronger during the $20^{\text {th }}$ century. The IPCC4 simulations of the $20^{\text {th }}$ and $21^{\text {st }}$ centuries do not show any significant change in the pattern of the teleconnections, but the dominant ENSO teleconnection also 
exhibits a significant strengthening, thereby suggesting that the observed trend could be partly a response to the anthropogenic forcing.

Finally, the MCA is also applied to the LF data. The first observed mode reveals a wellknown inter-hemispheric SST pattern that is strongly related to the multi-decadal variability of the WAM rainfall dominated by the severe drying trend from the 1950s to the 1980s. Whereas recent studies suggest that this drying could be partly caused by anthropogenic forcings, only five among the twelve IPCC4 models capture some features of this LF coupled mode. This result suggests the need for a more detailed validation of the WAM variability, including a dynamical interpretation of the SST-rainfall relationships. 


\section{Introduction}

For demographic, socio-economic and climatic reasons, West Africa is probably one of the most vulnerable regions in the world as far as water resources and food production are concerned. Unfortunately, it is also one of the regions where the precipitation response to the anthropogenic climate change is the most uncertain (Douville et al. 2006a). This might be attributed to the complex interactions that control the observed West African monsoon climate, including both regional processes such as a strong land surface coupling (Koster et al. 2004), and remote effects such as a strong sensitivity to tropical SSTs (Giannini et al. 2005). As such, West Africa provides an excellent test bed for evaluating the capability of coupled OAGCMs in simulating regional climate variability.

Sahel is the region of the globe that has experienced the strongest decrease in rainfall over the second half of the $20^{\text {th }}$ century. As shown in Fig. 1a, a persistent drying was observed from the 1950 s to the 1980 s, followed by a partial recovery of the summer monsoon precipitation in the last decade. Anticipating whether this recovery will carry on or whether the rainfall deficit will on the contrary intensify over the $21^{\text {st }}$ century is therefore a crucial challenge for the modelling community. Besides its multi-decadal modulation, the WAM precipitation also shows a strong interannual variability that can lead to extremely dry years with dramatic impacts on the regional food production. Predicting such extreme climate events and possible changes in their frequency and/or severity is also of paramount importance.

Following Charney (1975) and Lamb (1978), two main research tracks have been explored to explain the WAM variability: land-atmosphere interactions on the one hand, and monsoon teleconnections with tropical SSTs on the other hand. Whereas the land surface track has not been abandoned, recent studies based on both observations and numerical experiments suggest that the oceanic forcing is a dominant one (Giannini et al. 2005, Douville et al. 2006b). This forcing has been widely documented over recent decades, using both observations and global atmospheric simulations driven by idealized or observed SSTs. Different basins have been 
studied either separately - the tropical Atlantic (Janicot 1992), the tropical Pacific (Janicot et al. 1996, Rowell 2001), the Indian Ocean (Bader and Latif 2003), and the Mediterranean (Rowell 2003) - or through comprehensive studies linking the observed monsoon rainfall to the global oceans (Folland et al. 1986, Rowell et al. 1995, Fontaine and Janicot 1996).

More recently, ensembles of transient atmospheric simulations driven by global monthly SSTs observed during the second half of the $20^{\text {th }}$ century have shown that various AGCMs are able to capture a significant part of both interannual and multi-decadal variability of the WAM, as well as some aspects of the teleconnections with tropical SSTs (Moron et al. 2004, Paeth and Friedrichs 2004, Giannini et al. 2005, Lu and Delworth 2005). While such studies demonstrate that the persistent Sahel drought was partly triggered by the tropical SST variability, they do not address the possible anthropogenic origin of this drying. Moreover, they do not account for the day-to-day ocean-atmosphere coupling that can affect the SST influence on the tropical variability, as revealed by the comparison between forced and coupled atmospheric simulations (Peña et al. 2003, Fu et al. 2002, Krishna Kumar et al. 2005, Douville 2005).

The recent simulations achieved in the framework of the $4^{\text {th }}$ Assessment Report of the IPCC represent a unique opportunity to explore the range of climate change projected by state-of-theart coupled OAGCMs. Several recent studies have been based on these simulations and have focused on the recent and/or future evolution of the WAM. In keeping with Fig. 2 in the present study, Douville et al. (2006a) showed that the annual mean precipitation response over West Africa in the transient SRES-A2 scenarios of the $21^{\text {st }}$ century is highly model-dependent. They also suggested that model deficiencies in simulating the ENSO teleconnections with tropical rainfall could be partly responsible for the model spread in their projection of global precipitation over land. Comparing preindustrial and $20^{\text {th }}$ century simulations, Biasutti and Giannini (2006) found that at least 30\% of the recent Sahel drying was externally forced. They emphasized the role of reflective aerosols that contribute to an inter-hemispheric SST gradient, which could be responsible for the persistent precipitation deficit. Lau et al. (2006) also conducted a multi-model study of the $20^{\text {th }}$ century simulations. While they surprisingly 
considered a priori that the Sahel drought could not be explained by the internal climate variability, their selection of coupled models that do simulate the $20^{\text {th }}$ century drying revealed the key teleconnections that control the multi-decadal variability of the WAM rainfall in the IPCC4 simulations, with a particular emphasis on the Indian and Atlantic tropical oceans. Looking specifically at ensembles of $20^{\text {th }}$ century simulations with two versions of the GFDL model, Held et al. (2006) showed that the Sahel drying trend is a robust feature of these models which is attributable partly to an increase in the aerosol loading and partly to an increase in greenhouse gases (GHG).

Such studies represent an important step in the evaluation of the WAM sensitivity to anthropogenic forcings. Nevertheless, while they do emphasize the relevance of the monsoonSST relationships in the detection of anthropogenic climate change over West Africa, none of them evaluates these relationships in the IPCC4 models. In the present study, we focus on the influence of tropical SSTs on the interannual and multi-decadal variability of the WAM precipitation. The simulated teleconnections are validated in twelve IPCC4 models using a Maximum Covariance Analysis (MCA, also called Singular Value Decomposition in early papers). To avoid spurious interactions between the interannual and multi-decadal time scales highlighted by the spectrum of the monsoon rainfall in Fig. 1b, the High-Frequency (HF) and Low-Frequency (LF) components of the WAM variability are analysed separately, as in the study of Ward (1998). This separation does not mean that there is no interaction between both time scales, but is justified by the fact that the LF fluctuations of the WAM cannot be simply interpreted as a modulation of the frequency or amplitude of its HF variability (Janicot et al. 2001).

The structure of the paper is as follows. Section 2 describes the data and the statistical techniques. Section 3 compares the HF teleconnections in observed and simulated data, as well as their LF modulation. Section 4 evaluates the models' ability to capture a LF relationship between the WAM rainfall and an inter-hemispheric mode of SST variability. 


\section{Data and methods}

\subsection{Observed data}

Two datasets are used in this study:

- The monthly mean precipitation dataset (1901-2002) provided for global land areas by the Climate Research Unit (New et al. 2000) at the $0.5^{\circ}$ resolution (CRU-P hereafter).

- The monthly mean SST climatology, HadISST1 (1870-2002), provided by the Hadley Centre (Rayner et al. 2003), interpolated onto a 128 by 64 horizontal grid to reduce the size of the SST matrix in the MCA computation (Had-SST hereafter).

The quality of the data has greatly increased during the second half of the century. However, the MCA yields quite similar results for both periods 1901-2002 and 1951-2002. Therefore the longest period, 1901-2002, was preferred for this study.

\subsection{Coupled models}

A subset of twelve models among the 22 currently available in the IPCC database has been used (http://www-pcmdi.llnl.gov/ipcc). An effort has been made to select models that have been widely used by the climate change community and that are really independent (the selection of two versions of the same model has been avoided). This subset is hopefully representative of the whole IPCC4 database. It is at least sufficient to illustrate the models' difficulty in simulating the WAM-SST teleconnections over the $20^{\text {th }}$ century and in predicting a consistent response to anthropogenic forcings. Table 1 describes the main features of the twelve coupled OAGCMs.

Three kinds of IPCC4 simulations have been used: 20C3M for the $20^{\text {th }}$ century, the SRESA2 scenario for the $21^{\text {st }}$ century, and one control (i.e. pre-industrial) run (CT) for each model. The IPCC SRES scenarios provide future anthropogenic emissions that have been converted in GHG concentrations and aerosol loadings as inputs for driving GCMs to produce climate 
change scenarios. The SRES-A2 scenario for the $21^{\text {st }}$ century is based on severe assumptions about demography, socio-economic development and technological change.

In the validation part, only one integration of each model has been considered (Tab. 1) given the robustness of the MCA results when applied to different sub-periods of the $20^{\text {th }}$ century integration or even to the pre-industrial or $21^{\text {st }}$ century climates. To assess possible changes in the HF teleconnections, available ensembles of parallel simulations with identical anthropogenic forcings have been used to assess the robustness of the results.

\subsection{Statistical tools}

\subsubsection{Data filtering}

First of all, JJAS (June to September) seasonal means have been computed for both precipitation and SST fields. It has been decided to focus on the summer monsoon season which indeed concentrates more than $80 \%$ of annual precipitation over Sahel. Since the main purpose of the paper is the validation of WAM-SST teleconnections against the $20^{\text {th }}$ century instrumental record, it has also been decided to filter any long-term change in both observed and simulated time series.

- Precipitation: All seasonal time series have been detrended linearly at each grid point.

- SST: The $20^{\text {th }}$ century time series have also been detrended linearly (validation of the HF modes), while for the concatenated $20^{\text {th }}$ and $21^{\text {st }}$ century IPCC4 time series (analysis of the LF modulation of HF modes and of the LF modes) a third order polynomial fit has been used in order to fit more closely the simulated SST warming.

The spectral analysis shown in Fig. 1b (performed with the Multi-Taper Method, see §2.3.5) indicates that observed rainfall over Sahel contains two distinct components, so that interannual variability can be easily isolated from the remainder of the spectrum prior to analysis. The use of a digital high-pass filter (Wallace et al. 1988) with a cut-off of ten years has been adopted, in 
order to separate the multi-decadal (referred to as the Low Frequency, LF) from the interannual (the High Frequency, HF). The choice of a ten-year cut-off has been made considering also the simulated rainfall indices: some models show a peak in their spectrum for periods between 10 and 20 years, which has to be distinguished from the interannual time scale.

The digital filter has been used at each grid-point as follows:

- The HF part of the time series is obtained by filtering the seasonal means.

- The LF part corresponds to the residual of the filtered anomalies.

Note that since the filtering reduces the length of the series (first and last fifteen years), the observed HF and LF series are limited to the 72-year period 1916-1987.

\subsubsection{Maximum Covariance Analysis}

Also called Singular Value Decomposition (SVD), the MCA is well discussed in Bretherton et al. (1992) and Wallace et al. (1992). The MCA can be considered as a generalization of the Principal Component Analysis (PCA), and indeed reduces to it when the two fields are identical. The MCA is usually applied to two data fields, in order to identify the pairs of coupled spatial patterns that explain the largest covariance between the two variables.

The MCA yields two sets of singular vectors and a set of singular values associated with each pair of vectors. Each pair of singular vectors describes a fraction of the square covariance between the two variables, and the Square Covariance Fraction (SCF) accounted for by the $\mathrm{k}^{\text {th }}$ pair of singular vectors is proportional to the square of the $\mathrm{k}^{\text {th }}$ singular value. The $\mathrm{k}^{\text {th }}$ Expansion Coefficient (EC) for each variable is computed by projecting the respective data field onto the $\mathrm{k}^{\text {th }}$ singular vector. The Correlation value (Corr) between the $\mathrm{k}^{\text {th }} \mathrm{ECs}$ of the two variables indicates how strongly related the coupled patterns are.

Using the ECs from the MCA, two types of regression maps can be generated: 
- The $\mathrm{k}^{\text {th }}$ homogeneous Vector $(\mathrm{hV})$ is the regression map between the grid point anomalies of a given field and its $\mathrm{k}^{\text {th }} \mathrm{EC}$. The $\mathrm{hV}$ indicates the geographical localization of the co-varying part between the field and its $\mathrm{k}^{\text {th }} \mathrm{EC}$.

- The $\mathrm{k}^{\text {th }}$ heterogeneous Vector (HV) is the regression map between the grid point anomalies of a given field and the $\mathrm{k}^{\text {th }} \mathrm{EC}$ of the other field. The HV indicates how well the grid point anomalies of one field can be predicted from the knowledge of the $\mathrm{k}^{\text {th }} \mathrm{EC}$ of the other field.

Both hVs and HVs have been extensively used in this study. However, as the HVs contain precious information about the possible interactions between the two fields, only HVs are shown in this paper.

Several geographical windows have been tested for the MCA calculations. Whereas the meridional boundaries of the SST domain has no influence on the first coupled modes, the choice of the precipitation window is more sensitive. With respect to Africa's geography, we have finally decided to consider a region limited by the Sahara to the north, the equator to the south, and the Darfur mountains to the east (cf. the dashed box in Fig. 3). This region will be called "West Africa” hereafter.

\subsubsection{Significance testing}

Statistical tests in MCA are generally based on a Monte Carlo method, by comparing the estimated square covariance to that of a randomly scrambled ensemble (Wallace et al. 1992). Here we use a moving block bootstrap approach as described in Wilks (1997). Each MCA is repeated 99 times, linking the original SST anomalies with randomly scrambled precipitation ones, so that the chronological order between the two fields is destroyed. To reduce the influence of serial correlation, blocks of two successive years are considered in the shuffling of the time sequence. Choices for the block length are usually qualitative in the literature. Von Storch and Zwiers (1999) advice that the block length should be related to the persistence of the process that has been sampled. In our case, blocks of two consecutive years are used for the HF 
data, and blocks of ten years for the LF. Significance levels are estimated for the SCF (respectively correlation) by the percentage of randomized SCF (respectively correlation) for the corresponding mode that exceeds the value being tested. Concerning heterogeneous maps, significance levels are estimated in each grid point using an ordinary permutation test with 99 shuffles (Von Storch and Zwiers 1999).

\subsubsection{VARIMAX rotation}

To guarantee the robustness of our results, the MCA outputs have been systematically compared to the following statistics:

- mean and standard-deviation maps of each field,

- a separate PCA of each field,

- a MCA with VARIMAX rotation of the first six pairs of singular vectors.

The spatial orthogonality of the singular vectors can be a strong and undesirable constraint on PCA and MCA, yielding patterns that may not correspond to physical modes. Thus, in order to assess the robustness of MCA results, the leading modes were subjected to a VARIMAX rotation following Cheng and Dunkerton (1995). The rotation creates indeed spatial patterns that are no longer orthogonal within each field but tend to have a larger amplitude in the regions where the covariance between the two fields is large. The number of pairs of singular vectors submitted to rotation has been tested in the observations: beyond five pairs of rotated vectors the results are quite insensitive to an increase in the number of pairs, and six pairs has been considered as a reasonable choice.

\subsubsection{Spectral analyses}

The spectral analyses performed in this study are based on the Multi-Taper Method (Ghil et al. 2002), hereafter MTM, and the confidence levels are obtained relative to an estimated red noise background (Mann and Lees 1996). The MTM aims at reducing the variance of spectral estimates by the use of three tapers, rather than the unique spectral window used by classical 
methods. Data are indeed premultiplied by orthogonal tapers constructed to minimize the spectral leakage due to the finite length of the time series, and a set of independent estimates of the power spectrum is then computed. The MTM describes structures that are modulated in frequency and amplitude, with an optimal trade-off between spectral resolution and variance.

\section{High frequency WAM-SST teleconnections}

\subsection{Observations}

\subsubsection{Two distinct modes of covariability}

The leading two modes of HF covariability obtained with the observed datasets explain $71 \%$ of the squared covariance between the JJAS precipitation and SST fields (the MCA regions are shown in Fig. 3). The total amount of variance explained by the two modes reaches $28 \%$ for the precipitation and $46 \%$ for the SSTs. The correlation between ECs, which is a good estimate of the strength of the coupling, is higher for the second mode and both correlations are significant at the $99 \%$ level. Fig. 3a shows the leading two HVs obtained with the filtered observations, and Fig. 4 shows the corresponding ECs.

- The first HF mode statistically links Sahelian rainfall variability with eastern Pacific SSTs. The sign of the loadings shows that El Niño events are significantly correlated to Sahelian droughts. The first SST EC displayed in Fig. 4 is strongly correlated to the HF JJAS Niño-3 index (correlation 0.95 significant at the 99\% level); this mode will thus be called "ENSO mode” hereafter.

- The second HF mode pictures the influence of the Gulf of Guinea on the monsoon. The precipitation pattern reveals that warmer than average SSTs in the Gulf of Guinea are strongly correlated with higher than average precipitation along the coast. This mode will be called "Gulf of Guinea mode” hereafter. 
The SCF significance obtained with the bootstrap is $68 \%$ for the first mode, $99 \%$ for the second mode, and less than $6 \%$ for the further modes in the MCA decomposition. While the first mode might correspond to a modulation of the monsoon activity by tropical east-Pacific SSTs, the second mode can be interpreted as a local modulation of the latitudinal position of the African rainbelt through Gulf of Guinea SSTs. These two observed HF teleconnections are fully consistent with the results of previous studies (Fontaine and Janicot 1996, Rowell et al. 1995, Ward 1998). Nevertheless, it seems important to assess carefully the robustness of the method before applying the MCA to the IPCC4 simulations.

\subsubsection{Robustness of the results}

The precipitation patterns in Fig. 3a are consistent with a simple PCA over the same domain (not shown). Even percentages of explained variance are roughly equal. Some sensitivity tests have also been conducted by varying the geographical and temporal windows in the MCA, without notable consequences on the results. For instance, a broader SST domain has been used in order to include the Mediterranean in the computation, but results were little affected by this change. The Mediterranean is indeed a region of likely influence on the WAM system (Rowell 2001), but its limited geographical extension might have lessened its impact in our large-scale MCA. Indeed, a pure Mediterranean teleconnection appears if the MCA is applied to a small SST domain that surrounds Africa, including the nearest parts of the Atlantic and Indian oceans: such a Mediterranean mode is actually linked to the north-eastern part of Sahelian precipitation (not shown).

Giannini et al. (2005) produced a PCA with historical precipitation records of 57 African stations during northern summer 1930-2000. The similar PCA applied to our gridded dataset yields very similar patterns and fractions of explained variance. Therefore, it can be asserted that the spatial distribution of the dataset has only a marginal effect on the results. Additionally, the MCA computed with the CRU-P dataset interpolated onto a 128 by 64 horizontal grid yields exactly the same results as with the finer resolution, which means that the method is not sensitive to the data resolution. This conclusion is particularly important since the IPCC4 
models have different atmospheric resolutions (from $1.4^{\circ} / 1.4^{\circ}$ to $5^{\circ} / 4^{\circ}$ in longitude/latitude), and the MCA will be performed directly on the original atmospheric model grid rather than on interpolated data.

Finally, a VARIMAX rotation has also been imposed to the first six singular vectors (Fig. 3b). Thereafter, the ENSO pattern gets a stronger core, and looses some of the low values in the Gulf of Guinea. The second SST mode does not change at all. As regards the precipitation HVs, the second mode gets its bipolarity strengthened, but in return the explained variance of precipitation decreases from $10 \%$ to $6 \%$ for the first mode. Correlations of the ECs are higher after the VARIMAX rotation, and Tab. 2 indicates that the SST EC1 is less correlated to EC2 with this method, and that the EC2 is more correlated to the Gulf of Guinea index displayed in Fig. 4. In conclusion, the VARIMAX rotation has a substantial influence on the EC time series, but the physical meaning of the leading two modes of covariability remains unchanged.

\subsection{IPCC4 simulations}

\subsubsection{Common features of the models}

In order to concentrate on the most significant teleconnections, we only take into account the coupled modes that explain more than $10 \%$ of precipitation and SST variance (P-Var and SSTVar), and with a SCF bootstrap significance greater than 50\%. These quantities are displayed in Fig. 5 for the first HF mode of the twelve IPCC4 $20^{\text {th }}$ century simulations. With our criterion, two models (CCCMA and GISS) do not have any significant mode, and only one model (GFDL) shows a second mode. Concerning the CCCMA and GISS simulations, the SST-Var cumulated by the leading two modes is lower than $15 \%$, while this sum ranges from $29 \%$ to $63 \%$ with the other models (46\% in the observations). This lack of SST variability is confirmed by a PCA applied to tropical SSTs, especially with the GISS model, that does not appear to simulate any ENSO variability, as was already noted by Guilyardi (2006). Consequently, the MCA was not able to detect any significant teleconnection with these two models. 
A common feature of the ten remaining models is that, whereas in the observed datasets the ratio SCF1 / SCF2 = 1.5, this value ranges from about 2.8 to 23.4 in the models, which means that the first mode is often highly predominant over the second one, and in four models, the SCF explained by the first mode exceeds $85 \%$. Similarly, the amount of precipitation variance accounted for by the first coupled mode is higher in the simulations, and exceeds $20 \%$ in six models out of ten, versus $10 \%$ in the observations. In summary, ten models (out of twelve) do simulate a significant WAM-SST teleconnection, that often explains most of the covariability between the two fields, and which is - in nine cases - the only significant relationship detected by the MCA.

\subsubsection{Description of the leading two HF modes}

In the $20^{\text {th }}$ century IPCC 4 simulations, the first mode of HF covariability always shows a strong teleconnection with the tropical Pacific (Fig. 6). The obtained SST patterns are generally in good agreement with the observations, but extend too far in the western Pacific and show spurious links with other oceanic basins. Looking at precipitation, teleconnections appear strongly model dependent and can be very different from the observed ones.

- Five models (CSIRO, INM, MIROC, MRI and UKMO) have a rather realistic ENSO-monsoon relationship: positive SST anomalies in the tropical Pacific are significantly correlated to negative precipitation anomalies over West Africa.

- In five cases (CNRM, GFDL, IPSL, MPI and NCAR) Pacific SST anomalies are significantly correlated to precipitation anomalies of the same (i.e. wrong) sign over West Africa.

Some of the teleconnections discarded above deserve further examination. In particular, the first mode of the CNRM and MPI simulations show similar problems in their SST and precipitation patterns. In both models, warm events in the tropical Pacific are associated with a drought in East Africa and a wet anomaly over West Africa, unlike the observations. Understanding the reasons for such a shift of the drought region would require a careful 
investigation of the simulated large-scale dynamics, which is beyond the scope of the present study. One hypothesis is that the unrealistic pattern of SST variability in the western Pacific is responsible for the wrong teleconnection. Note however that a realistic Pacific SST variability (isolines in Fig. 6) does not necessarily leads to a realistic teleconnection with the WAM rainfall, as indicated by the results of the IPSL and NCAR simulations.

Moving to the second mode, the MCA results indicate that state-of-the-art coupled AOGCMs have great difficulties in simulating the observed relationship between the northward migration of the WAM rainfall belt and the SST over the Gulf of Guinea, as a self-controlled mode of variability that is not associated with the ENSO. With our criterion, only the GFDL CM2.0 model shows a significant second coupled mode. This mode is displayed in Fig. 7 and looks quite realistic compared to the observed one (Fig. 3b). Note that in Fig. 7, HVs are displayed after a VARIMAX rotation in order to get more spatially localized patterns (§2.3.4). Thereafter, the first SST mode is slightly different than in Fig.6 with this model: the rotated Pacific SST pattern actually looses its dipolar counterpart in the Atlantic.

\subsubsection{Analysis of the EC time-series (first mode only)}

As it would be meaningless to compare directly the ECs of the different simulations since they have different time histories and phase relationships, we have used the MTM to analyse the amplitude spectrum of the time series (see §2.3.5). Here the analysis is restricted to the five models that have been shown to simulate reasonably well the first teleconnection. Tab. 3 gives the significant periods of the spectrum for both ECs of the first mode. As a consequence of the MCA and because of the prior filtering, most of the significant periods of the precipitation EC can be found in the spectrum of the SST EC. In the observations, periods $3.6 y$ and $5.2 \mathrm{y}$ correspond to the ENSO: Fedorov and Philander (2001) have shown that the 5.2y peak is for the recent period (since the 1980s), and the 3.5y peak for the preceding period. In the models, the spectra of the precipitation and SST ECs show at least two common peaks, but periods do not correspond in the details to those observed. In particular, the INM and MIROC models have a significant peak around 7y (obvious when considering directly the spectra), and in the MRI 
model all common periods are lower than 3.6y. In conclusion, the spectra of the first ECs exhibit some realistic periods, but with noticeable differences among the five selected models, and only limited agreement with the observations.

\subsection{LF modulation of the HF teleconnections}

\subsubsection{Observations}

Several studies have suggested that the strength of the WAM-SST teleconnections has changed over the second half of the $20^{\text {th }}$ century. Janicot et al. (1996 and 2001) pointed out that the relationship between the ENSO and Sahel rainfall was dominant during the drought period, whereas during the wetter 1950-70 period, the association with the tropical Atlantic prevailed. The modulation of ENSO teleconnections and the possible reasons for such variations were further discussed by Ward (1998), Diaz et al. (2001), Rowell (2001). Two main hypotheses were proposed: a change in the background state (mean climate) and a change in the ENSO variability (pattern, magnitude, frequency and persistence of tropical Pacific SST anomalies).

Whatever the mechanism is, such a modulation is not sufficient to explain the persistence and magnitude of the drying trend observed over West Africa from the 1950s to the 1980s (Janicot 2001). Nevertheless, it is interesting to investigate whether it might be considered as a possible evidence of anthropogenic climate change. Note that the aim is not to address the difficult question of detecting climate change at the regional scale, but simply to compare the LF evolution of the HF modes of covariability between models and observations.

As the correlation between ECs tells about the strength of the coupling between the two patterns, Fig. 8 shows the 29-year running correlations between SSTs and precipitation ECs. Note that VARIMAX-rotated ECs have been used, as it proved to better separate Atlantic and Pacific HF signals (end of §3.1.2). Fig. 8 indicates that the influence of SSTs on the WAM has increased over the second half of the $20^{\text {th }}$ century for both HF modes: 
- For the ENSO teleconnection, such an evolution is consistent with previous studies and confirms that the ENSO teleconnection has been strengthening over recent decades.

- For the Atlantic teleconnection, an increase is also found that is in good agreement with Rowell (2001), but in our study the prior filtering reduces the length of the series. Fig. 8 also shows the running correlations calculated with unfiltered data (but with prior linear detrending). It confirms the slight decrease in the 1980s found in Rowell (2001) and Janicot et al. (2001), i.e. a weakening of the Atlantic teleconnection at the end of the $20^{\text {th }}$ century.

Given the relatively short and heterogeneous instrumental record, the statistical significance of the observed change in the ENSO-monsoon teleconnection remains uncertain (Rowell 2001, Janicot et al. 2001, Van Oldenborgh and Burgers 2005). Numerical studies are therefore necessary for a better understanding of this variability. Moron et al. (2003) have compared Sahel rainfall variability in four AGCMs forced by prescribed observed SSTs and have shown that the models fail to reproduce the observed modulation of the SST-rainfall teleconnection. To our knowledge, coupled OAGCMs have never been evaluated in this respect (at least on a multi-model basis), as it is proposed in the following paragraph for the five models that have been selected in our study and have been shown to achieve a realistic simulation of the ENSOmonsoon teleconnection patterns.

\subsubsection{IPCC4 simulations}

The IPCC4 database gives us the opportunity to analyse preindustrial, $20^{\text {th }}$ century and $21^{\text {st }}$ century climate simulations so as to better assess the significance of a possible influence of anthropogenic forcings on the ENSO-monsoon teleconnection. First, the MCA has been calculated over the $21^{\text {st }}$ century simulations for the five selected models. The modes obtained over the $21^{\text {st }}$ century are very similar to those obtained over the $20^{\text {st }}$ century simulations. This result confirms the study of Camberlin et al. (2004), based on a single model, according to 
which the general patterns of ENSO-rainfall teleconnections would undergo little change under increased concentrations of GHG. As a result, the MCA was recalculated over the whole 19012100 period, so as to take advantage of the length of the simulations. As with the observations, the strength of the detected teleconnections has been calculated using 29-year running correlations between ECs (Fig. 9). To test the robustness of the results, the analysis has been applied to the whole ensemble of available simulations for the MIROC and MRI models, i.e. the three parallel simulations of the $20^{\text {th }}$ and $21^{\text {st }}$ centuries with identical radiative forcings.

Two distinct features of the evolution of the simulated ENSO-monsoon teleconnection can be distinguished in Fig. 9. First, there is a strong natural LF modulation of the teleconnection, whose magnitude is relatively consistent with the limited instrumental record. In one integration of the MIROC model, the ENSO teleconnection even vanishes during some periods of more than fifty years. Similar fluctuations are also found in the control pre-industrial runs (not shown) and cannot be attributed to any anthropogenic forcing. It is beyond the scope of the study to investigate the physical mechanisms that control this LF modulation of the teleconnection. However, in some models (especially MRI and CSIRO), the modulation of the ENSO variability seems to have a greater influence than the evolution of the background state (not shown).

In addition to this strong natural variability, a long-term trend in the strength of the ENSOmonsoon teleconnection is also noticeable. Linear trends have been estimated and summarized in Table 4. Except in the UKMO simulation, they are always significantly positive, which indicates a strengthening of the ENSO-monsoon teleconnection.

Table 4 also shows the lowest and highest trends found in the control (preindustrial) run for each model. These trends have been estimated over a sliding window of the same length as the concatenated $20^{\text {th }}$ and $21^{\text {st }}$ century in the SRES-A2 scenario. In seven scenarios out of nine, the trend is greater than the highest trend found in the control run. Once more, such results do not clearly demonstrate that the strengthening found in the instrumental record was caused by anthropogenic forcings, but it suggests that teleconnections are not only a test bed for validating 
the model variability at the interannual time scale, but also for testing the model sensitivity at the climate change time scale. Note also that the prescribed anthropogenic forcings are particularly strong in the SRES-A2 simulations and that the model response could be weaker in alternative climate scenarios.

Finally, it must be emphasized that the response of the ENSO itself is still a matter of debate. On the one hand, Van Oldenborgh et al. (2005) assessed various ENSO characteristics in the IPCC4 SRES-A2 simulations and concluded that the possible changes are of the same magnitude as the observed decadal variability over the $20^{\text {th }}$ century, and are thus not statistically significant. On the other hand, Guilyardi (2006) found a positive trend in the ENSO amplitude in IPCC4 double and quadruple CO2 stabilized scenarios, with a mode change that is consistent with the observed 1976 shift. It could be therefore interesting to assess the ENSO-monsoon teleconnections in such stabilized experiments in order to weaken the signal-to-noise problem inherent to transient simulations.

\section{Low frequency WAM-SST teleconnections}

As detailed in §2.3.1, the high and low-frequency components of the SST and precipitation time series have been distinguished from the beginning of the study (with a cut-off period of 10 years). Here we look for a possible covariability between the LF variations of global SSTs and West African precipitation, using the same MCA technique as in section 3. Note that the SST domain has been widened to latitudes $50^{\circ} \mathrm{S}$ and $50^{\circ} \mathrm{N}$ in order to take into account most of the world ocean. For the sake of simplicity, and because of the reduced degrees of freedom, only the first mode of covariability will be considered.

\subsection{Observations}

In the observations, the first LF coupled mode accounts for $74 \%$ of SCF, and for high amounts of explained variance (Fig. 10). The EC correlation is of 0.94 (significant at the 99\% level), which implies a very strong relationship. The precipitation EC in Fig. 11 corresponds - 
when multiplied by the negative sign of the corresponding singular vector - to the well known Sahelian precipitation trend during the second half of the century, while the SST EC combined with the SST pattern in Fig. 10 suggests a concomitant warming of the southern hemisphere and a cooling of the northern SSTs. This SST pattern corresponds to a well-known interhemispheric pattern (Folland et al. 1986, Rowell et al. 1995) with two maxima: one located in the southern Indian Ocean, and the other situated in the North Pacific basin. Deser et al. (2004) provided observational evidence of such multi-decadal SST fluctuations in the Indian Ocean using a 194-yr coral record. Besides, the potential impact of the Indian Ocean at multi-decadal time scales has been recently detailed by Bader and Latif (2003), Giannini et al. (2005), Lu and Delworth (2005), but a possible influence of the North Pacific summer SSTs on the African monsoon multi-decadal variations is less documented.

This MCA of the observed LF component confirms the association between the $20^{\text {th }}$ century Sahelian drought and an inter-hemispheric temperature contrast that inhibits the convection in the rainbelt. However, at this decadal time scale, there are too few degrees of freedom to make firm conclusions about teleconnection mechanisms based on statistics alone. Therefore, it is interesting to search for multi-decadal coupled modes in our set of coupled OAGCM simulations from about 1860 to 2100.

\subsection{IPCC4 simulations}

As in the HF analysis, we only take into account the dominant teleconnections that explain more than $10 \%$ of precipitation and SST variance, and with a SCF bootstrap significance greater than $50 \%$. As pictured by Fig. 12, this is generally the case, except for the five following models: CCCMA, CNRM, GFDL, GISS and NCAR.

The first pairs of HVs are displayed in Fig. 13 for the seven remaining models. Besides their geographical distribution, the zonal mean behaviour of the SST HVs is also shown given the relative zonal symmetry of the simulated patterns. Only five models exhibit some similarities with the observations (INM, MIROC, MPI, MRI, UKMO). Most of them confirm that - at the 
multi-decadal time scale - a dry spell in West Africa is associated with a warm equatorial Pacific, a warm East Indian ocean, a cold phase in the northern Pacific, and a dipolar northsouth pattern in the Atlantic (only for MPI, MRI and UKMO). Corresponding ECs are presented in Fig. 14 and can be compared to the observed ECs in Fig. 11. The five selected models tend to exhibit shorter than observed oscillations over the $20^{\text {th }}$ century.

Looking at the zonal mean signature of the SST HVs, most models highlight a tropicalextratropical rather than an inter-hemispheric SST contrast. Three models (MPI, MRI and UKMO) however clearly show a meridional asymmetry with a stronger signal in the Northern rather than the Southern Hemisphere. This is obviously a consequence of the lack of a southern Indian ocean maximum in the models (which is the most significant pattern in the observations). Note also that for the models, results are similar in the control simulations (not shown), which demonstrates that this multi-decadal SST variability is mainly internal to the climate system. The SST-rainfall coupling is generally weaker than in the observations, as indicated by the EC correlations provided in Fig. 13. The magnitude of the LF rainfall patterns revealed by the MCA is also weaker, but is generally not negligible compared to the rainfall anomalies that are produced at the end of the 21st century in the SRES A2 scenarios. This remark emphasizes the need for the climate community to better understand and validate the internal modes of LF variability to get more confident in the model projections.

\section{Conclusion}

West Africa is a region of high demography in a fragile environment, where climate forecasting is a research priority at both seasonal and multi-decadal time scales. In the IPCC4 climate scenarios of the $21^{\text {st }}$ century, the response of the WAM precipitation is still highly model-dependent. While a majority of models indicates that the late $20^{\text {th }}$ century anthropogenic forcings may have contributed to the Sahel drying (Biasutti and Giannini 2006), it is not so clear that this drying will carry on during the $21^{\text {st }}$ century (Douville et al. 2006a). Given the contrasted evolution of aerosol and GHG emissions in the SRES A2 scenarios (as well as in 
most IPCC scenarios), this result suggests that sulphate aerosols are mainly responsible for the $20^{\text {th }}$ century response and/or that the WAM response to increasing amounts of GHG is highly non-linear.

This remark highlights the difficulty to reduce uncertainties in the $21^{\text {st }}$ century climate scenarios. In particular, simulating the $20^{\text {th }}$ century Sahel drought is probably not sufficient to constrain the models' response (Lau et al. 2006). Comparing paleoclimate simulations to proxy is also not sufficient since the models' sensitivity at the regional scale might be highly dependent on the nature and magnitude of the external forcing applied to the global climate system. There is therefore no unique and magic solution to constrain the models' response, but the need for testing the models on a wide range of processes and time scales. In this respect, validating SST-rainfall teleconnections is particularly attractive for at least two reasons. On the one hand, such teleconnections clearly contribute to the observed climate variability at interannual and multi-decadal time scales and their evolution might therefore influence the $21^{\text {st }}$ century climate projections. On the second hand, such teleconnections are mainly controlled by the large-scale atmospheric dynamics and therefore represent much more than a validation of SST and rainfall variability.

The present study was aimed at evaluating how state-of-the-art coupled AOGCMs simulate teleconnections between tropical SSTs and the African monsoon, treating separately the HF (i.e. interannual) and LF (i.e. multi-decadal) variability. Given this partition, the results confirm that the WAM precipitation is significantly connected to regional and global SST anomalies on both time scales. First applied on the observed HF time series, the Maximum Covariance Analysis (MCA) actually provides a synthetic description of two well-established teleconnections that explain together $28 \%$ of the WAM interannual rainfall variability over the $20^{\text {th }}$ century. The leading HF modes are generally too strong in the simulations, except for two models that do not exhibit any discernable HF coupling. Above all, the HV patterns look quite different from a model to another and only five simulations reproduce a WAM-SST relationship of the correct sign. Finally, only one model exhibits a significant second mode. At the LF time scale, the 
MCA identifies a well-known inter-hemispheric SST contrast, that is poorly reproduced by the models. While several studies (Rotstayn and Lohmann 2002, Held et al. 2005, Biasutti and Giannini 2006) have suggested that the $20^{\text {th }}$ century aerosol forcing could be partly responsible for the observed zonal mean SST gradient, our results emphasize the need for a better understanding of the natural multi-decadal variability of the WAM for confirming such an hypothesis.

In addition, it has been shown that the strength of the Pacific-WAM HF teleconnection is not stationary. In the IPCC4 simulations, a large fraction of this multi-decadal modulation is obviously not due to the anthropogenic forcings. Nevertheless, most models that show a reasonable simulation of the ENSO-monsoon teleconnection also simulate a significant strengthening of this relationship that is not found in the preindustrial runs and is consistent with the trend estimated from the instrumental record.

In spite of this, the main conclusion of the study is that many models are still unable to capture the main modes of SST-WAM rainfall covariability. In some cases, this problem could be related to some deficiencies in the model's climatology. For instance, HF patterns in the CNRM and NCAR simulations have obviously their origin in the simulated rainfall climatology (isolines in Fig. 6). Conversely, a realistic teleconnection is not always associated with a good climatology. For instance, the MIROC model shows a reasonable HF teleconnection pattern, but strongly overestimates the monsoon rainfall and its variability. Moreover, it must be emphasized that the four models (GFDL, MPI, MRI and UKMO) that best simulate the tropical Pacific climatology according to Guilyardi (2006) do not correspond exactly to the five models (CSIRO, INM, MIROC, MRI and UKMO) that have a realistic ENSO coupled mode in our analysis. It is therefore now necessary to go a step further in the model validation and to analyse more thoroughly the large-scale dynamics that control the teleconnections even if the available atmospheric analyses are too short to tell anything about the LF variability. 


\section{Acknowledgments}

This work was supported by the AMMA program (African Monsoon Multidisciplinary Analysis), and by the ENSEMBLES European project (contract GOCE-CT-2003-505539). The authors are grateful to all IPCC4 participants and to the PCMDI for the build up of the IPCC4 database. The figures have been prepared using GrADS software, and the MTM tool was found on the Web site http://www.atmos.ucla.edu/tcd/ssa/. Thanks are also due to Fabrice Chauvin for his comments, and Serge Janicot for improving the original manuscript. Finally, we acknowledge the two anonymous reviewers for their constructive criticisms and suggestions.

\section{References}

Bader J, Latif M (2003) The impact of decadal-scale Indian Ocean Sea Surface Temperature anomalies on Sahelian rainfall and the North Atlantic Oscillation. Geophysical Research Letters 30, 2169, DOI: 10.1029/2003GL018426

Biasutti M, Giannini A (2006) Robust Sahel drying in response to late $20^{\text {th }}$ century forcings. Geophysical Research Letters 33, L11706, DOI: 10.1029/2006GL026067

Bretherton CS, Smith C, Wallace JM (1992) An intercomparison of methods for finding coupled patterns in climate data. Journal of Climate 5: 541-560

Camberlin P, Chauvin F, Douville H, Zhao Y (2004) Simulated ENSO-tropical rainfall teleconnections in present-day and under enhanced greenhouse gases conditions. Climate Dynamics 23: 641-657

Charney JG (1975) Dynamics of deserts and drought in the Sahel. Quarterly Journal of the Royal Meteorological Society 428: 193-202

Cheng X, Dunkerton TJ (1995) Orthogonal rotation of spatial patterns derived from Singular Value Decomposition analysis. Journal of Climate 8: 2631-2643

Deser C, Phillips AS, Hurrell JW (2004) Pacific interdecadal climate variability: linkages between the tropics and the North Pacific during boreal winter since 1900. Journal of Climate 17: 3109-3124

Diaz HF, Hoerling MP, Eischeid JK (2001) ENSO variability, teleconnections and climate change. International Journal of Climatology 21: 1845-1862

Douville H (2005) Limitations of time-slice experiments for predicting regional climate change over South Asia. Climate Dynamics 24: 373-391

Douville H, Salas-Mélia D, Tyteca S (2006a) On the tropical origin of uncertainties in the global land precipitation response to global warming. Climate Dynamics 26: 367-385

Douville H, Conil S, Tyteca S, Voldoire A (2006b) Soil moisture memory and West African monsoon predictability: artefact or reality ? Climate Dynamics (submitted) 
Fedorov AV, Philander SG (2001) A stability analysis of tropical ocean-atmosphere interactions: bridging measurements and theory for El Niño. Journal of Climate 14: 3086-3101

Folland CK, Palmer TN, Parker DE (1986) Sahel rainfall and worldwide Sea Temperatures. Nature 320: 602-607

Fontaine B, Janicot S (1996) Sea Surface Temperature fields associated with West African rainfall anomaly types. Journal of Climate 9: 2935-2940

Fu X, Wang B, Li T (2002) Impacts of Air-Sea coupling on the simulation of mean Asian summer monsoon in the ECHAM4 model. Monthly Weather Review 130: 1889-2904

Ghil M, Allen MR, Dettinger MD, Ide K, Kondrashov D, Mann ME, Robertson AW, Saunders A, Tian Y, Varadi F, Yiou P (2002) Advanced spectral methods for climatic time series. Reviews of Geophysics 40: 3-1

Giannini A, Saravanan R, Chang P (2005) Dynamics of the boreal summer African monsoon in the NSIPP1 atmospheric model. Climate Dynamics 25: 517-535

Guilyardi E (2006) El Niño - mean state - seasonal cycle interactions in a multi-model ensemble. Climate Dynamics 26: 329-348

Held IM, Delworth TL, Lu J, Findell KL, Knutson TR (2005) Simulation of Sahel drought in the $20^{\text {th }}$ and $21^{\text {st }}$ centuries. PNAS 102: 17891-17896

Janicot S (1992) Spatiotemporal variability of West African rainfall. Part II: Associated surface and airmass characteristics. Journal of Climate 5: 499-511

Janicot S, Moron V, Fontaine B (1996) Sahel droughts and ENSO dynamics. Geophysical Research Letters 23: 515-518, DOI: 10.1029/96GL00246

Janicot S, Trzaska S, Poccard I (2001) Summer Sahel-ENSO teleconnection and decadal time scale SST variations. Climate Dynamics 18: 303-320

Koster RD, and the GLACE team (2004) Regions of strong coupling between soil moisture and precipitation. Science, 305, 1138-1141

Krishna Kumar K, Hoerling M, Rajagopalan B (2005) Advancing dynamical prediction of Indian monsoon rainfall. Geophysical Research Letters 32: L8704, DOI: 10.1029/2004GL021979

Lamb PJ (1978) Case studies of tropical Atlantic surface circulation patterns during recent sub-saharan weather anomalies: 1967 and 1968. Monthly Weather Review 106: 482491

Lau KM, Shen SSP, Kim KM, Wang H (2006) A multimodel study of the twentiethcentury simulations of Sahel drought from the 1970s to 1990s. Journal of Geophysical Research (Atmospheres) 111: D071111, DOI: 10.1029/2005JD006281

$\mathrm{Lu}$ J, Delworth TL (2005) Oceanic forcing of the late 20th century Sahel drought. Geophysical Research Letters 32: L22706, DOI: 10.1029/2005GL023316

Mann ME, Lees JM (1996) Robust estimation of background noise and signal detection in climatic time series. Climatic Change 33: 409-445

Moron V, Philippon N, Fontaine B (2003) Skill of Sahel rainfall variability in four atmospheric GCMs forced by prescribed SST. Geophysical Research Letters 30: 2221, DOI: 10.1029/2003GL018006

Moron V, Philippon N, Fontaine B (2004) Simulation of West African monsoon circulation in four atmospheric general circulation models forced by prescribed Sea Surface Temperature. Journal of Geophysical Research (Atmospheres) 109: D24105, DOI: $10.1029 / 2004 D J 004760$ 
New M, Hulme M, Jones P (2000) Representing twentieth-century space-time climate variability. Part II: Development of 1901-96 monthly grids of terrestrial surface climate. Journal of Climate 13: 2217-2238

Paeth H, Friederichs P (2004) Seasonality and time scales in the relationship between global SST and African rainfall. Climate Dynamics 23: 815-837

Peña M, Kalnay E, Cai M (2003) Statistics of locally coupled ocean and atmosphere intraseasonal anomalies in reanalysis and AMIP data. Nonlinear Processes in Geophysics 10: 245-251

Rayner NA, Parker DE, Horton EB, Folland CK, Alexander LV, Rowell DP, Kent EC, Kaplan A (2003) Global analyses of Sea Surface Temperature, sea ice, and night marine air temperature since the late nineteenth century. Journal of Geophysical Research (Atmospheres) 108: 4407, DOI: 10.1029/2002JD002670

Rotstayn LD, Lohmann U (2002) Tropical rainfall trends and the indirect aerosol effect. Journal of Climate 15: 2103-2116

Rowell DP, Folland CK, Maskell K, Ward NM (1995) Variability of summer rainfall over tropical north Africa (1906-92): observations and modelling. Quarterly Journal of the Royal Meteorological Society 121: 669-704

Rowell DP (2001) Teleconnections between the tropical Pacific and the Sahel. Quarterly Journal of the Royal Meteorological Society 127: 1683-1706

Rowell DP (2003) The impact of Mediterranean SSTs on the Sahelian rainfall season. Journal of Climate 16: 849-862

Van Oldenborgh GJ, Burgers G (2005) Searching for decadal variations in ENSO precipitation teleconnections. Geophysical Research Letters 32: L15701, DOI: 10.1029/2005GL023110

Van Oldenborgh GJ, Philip S, Collins M (2005) El Niño in a changing climate: a multimodel study. Ocean Science Discussions 2:267-298

Von Storch H, Zwiers FW (1999) Statistical analysis in climate research. Cambridge University Press

Wallace JM, Lim GH, Blackmon ML (1988) Relationship between cyclone tracks, anticyclone tracks and baroclinic waveguides. Journal of Atmospheric Sciences 45: 439-462

Wallace JM, Smith C, Bretherton CS (1992) Singular Value Decomposition of wintertime Sea Surface Temperature and 500-mb height anomalies. Journal of Climate 5: 561576

Ward MN (1998) Diagnosis and short-lead time prediction of summer rainfall in tropical North Africa at interannual and multidecadal timescales. Journal of Climate 11: 3167-3191

Wilks DS (1997) Resampling hypothesis tests for autocorrelated fields. Journal of Climate 10: 65-82 


\section{Table captions}

Tab. 1: Some features of the coupled models used in this study.

- Horizontal and vertical configurations,

- Equilibrium sensitivity to CO2 doubling,

- Types of anthropogenic aerosols (SU: sulfates, B\&OC: black and organic carbons),

- Parameterizations of aerosols effects (D: direct, SD: semi-direct, I1: first indirect, I2: second indirect),

- Other forcings used in the $20^{\text {th }}$ century simulations (V: volcanoes, S: solar, LU: landuse).

Tab. 2: Some correlations after the MCA of observed HF datasets (correlations are crossed when not significant at the 95\% level with the permutation test). The Niño-3 and Gulf of Guinea (GG) indices are based on the HF JJAS anomalies.

Tab. 3: Significant periods (in years) extracted from the MTM spectrum of the first pair of ECs. Significance level is 90\% (light grey), 95\% (medium grey) or 99\% (dark grey).

Tab. 4: Linear trends of the curves in Fig. 9. The estimated trends are expressed in \% per century, and the underlined values in the last column correspond to the trend of the ensemble mean (red curve in Fig. 9). Note that all the linear trends are significant at the $95 \%$ level (permutation test). Square brackets indicate the lowest and highest trend found in the control run of the model, for a time window of the same length as the concatenated $20^{\text {th }}$ and $21^{\text {st }}$ centuries.

\section{Figure captions}

Fig. 1: a) Sahel JJAS rainfall index (latitudes $10^{\circ} \mathrm{N}-20^{\circ} \mathrm{N}$ and longitudes $20^{\circ} \mathrm{E}-40^{\circ} \mathrm{W}$ ) with respect to the 1971-2000 mean, and b) its Multi-Taper Method (MTM) spectrum, calculated with the 1901-2002 CRU-P dataset, with prior linear detrending.

Fig. 2: Low-frequency signals extracted by digital filtering (ten year cut-off) of the Sahel JJAS rainfall index, for the SRES-A2 scenario of the twelve selected IPCC4 coupled models. The anomalies are displayed relatively to the 1971-2000 climatology of the model.

Fig. 3: MCA of the precipitation (left) and SST (right) observed CRU-P and Had-SST HF datasets without a) and with b) VARIMAX rotation. Colour shades indicate the value of the Heterogeneous Vector in each grid point where the correlation is significant at the $95 \%$ level (permutation test). For the precipitation, the three isolines indicate the mean 1951-2000 climatology with contours for the isohyets 0.5 (dotted), 3.0 (dashed) and $8.0 \mathrm{~mm} \cdot \mathrm{d}^{-1}$. For the SSTs, the three isolines indicate the SST standard deviations with contours for the isotherms $0.6^{\circ} \mathrm{C}, 0.8^{\circ} \mathrm{C}$ and $1.0^{\circ} \mathrm{C}$. A dashed box outlines the geographical areas taken into account for the 
calculation (latitudes $1.4^{\circ} \mathrm{S}-23.5^{\circ} \mathrm{N}$ and longitudes $19.5^{\circ} \mathrm{W}-22.5^{\circ} \mathrm{E}$ for the precipitation, and latitudes $32^{\circ} \mathrm{S}-32^{\circ} \mathrm{N}$ for the SSTs).

Fig. 4: ECs (normalized units) yielded by the MCA of the precipitation (left) and SST (right) observed HF datasets. The solid circles indicate a Niño-3 JJAS HF index superimposed on the SST-EC1, and a Gulf of Guinea index (latitudes $25^{\circ} \mathrm{S}-10^{\circ} \mathrm{N}$ and longitudes $20^{\circ} \mathrm{W}-15^{\circ} \mathrm{E}$ ) JJAS HF index superimposed on the SST-EC2.

Fig. 5: A colour-chart based description of the first HF mode in the models. Colours correspond to the SCF significance level, and to different thresholds of variance, as shown in the legend.

Fig. 6: Same as Fig. 3a, but for the first HF mode in the models.

Fig. 7: Same as Fig. 3b, but for the leading two HF modes of the GFDL model.

Fig. 8: Evolution of the coupling strength: 29-year running correlations between SST and precipitation ECs for the first (solid) and second (dashed) HF modes in the observations (maroon lines). Results of the same calculation, but with the raw data (no filtering), are displayed in turquoise.

Fig. 9: Same as Fig. 8, but for the first HF mode in the models. Symbols are solid when correlations are significant at the 95\% level (permutation test). For each graph, the red curve is the mean of the ensemble over the shared period. The dashed lines correspond to the time window displayed in Fig. 8.

Fig. 10: MCA of the precipitation (left) and SST (right) observed CRU-P and Had-SST LF datasets. Colour shades indicate the value of the Heterogeneous Vector in each grid point where the correlation is significant at the 95\% level (permutation test). A dashed box outlines the geographical areas taken into account for the calculation (latitudes $1.4^{\circ} \mathrm{S}-23.5^{\circ} \mathrm{N}$ and longitudes $19.5^{\circ} \mathrm{W}-22.5^{\circ} \mathrm{E}$ for the precipitation, and latitudes $50^{\circ} \mathrm{S}-50^{\circ} \mathrm{N}$ for the SSTs).

Fig. 11: ECs (normalized units) associated with the first LF mode in the observations.

Fig. 12: Same as Fig. 5, but for the first LF mode in the models.

Fig. 13: Same as Fig. 10, but for the first LF mode in the models.

Fig. 14: Same as Fig. 11, but for the models. 


\section{Tables}

Tab. 1

\begin{tabular}{|c|c|c|c|c|c|c|}
\hline $\begin{array}{l}\text { BRIEF } \\
\text { NAME }\end{array}$ & FULL NAME & \begin{tabular}{|c|} 
ATMOSPHERIC \\
CONFIGURATION \\
\end{tabular} & $\begin{array}{c}\Delta \mathbf{T} \\
\mathbf{K} /\left(\mathbf{W} / \mathbf{M}^{2}\right)\end{array}$ & $\begin{array}{l}\text { ANTHROP. } \\
\text { AEROSOLS }\end{array}$ & $\begin{array}{l}\text { AEROSOLS } \\
\text { EFFECTS }\end{array}$ & \begin{tabular}{|c|} 
OTHER \\
FORCINGS \\
\end{tabular} \\
\hline CCCMA & cccma_cgcm3 & \begin{tabular}{|c|} 
T47 L31 \\
\end{tabular} & $?$ & ? & $?$ & ? \\
\hline CNRM & cnrm_cm3 & T42 L45 & $?$ & SU & $\mathrm{D}$ & - \\
\hline CSIRO & csiro_mk3_0 & T63 L18 & 0.88 & SU & $\mathrm{D}$ & - \\
\hline GFDL & gfdl_cm2_0 & $2.5^{\circ} * 2^{\circ} \mathrm{L} 24$ & 0.80 & SU, B\&OC & $\mathrm{D}$ & $\mathrm{V}, \mathrm{S}, \mathrm{LU}$ \\
\hline GISS & giss_model_e_r & $5^{\circ * 4^{\circ} \mathrm{L} 15}$ & $?$ & SU, B\&OC & $\mathrm{D}, \mathrm{I} 1, \mathrm{I} 2$ & $\mathrm{~V}$ \\
\hline INM & inmcm3_0 & $5^{\circ} * 4^{\circ} \mathrm{L} 21$ & 0.52 & SU & $\mathrm{D}$ & $\mathrm{V}$ \\
\hline IPSL & ipsl_cm4 & $3.75^{\circ} * 2.5^{\circ} \mathrm{L} 19$ & 1.26 & SU & $\mathrm{D}, \mathrm{I} 1$ & - \\
\hline MIROC & miroc3_2_medres & T42 L20 & 1.3 & SU, B\&OC & $\mathrm{D}, \mathrm{I} 1, \mathrm{I} 2$ & $\mathrm{~V}, \mathrm{~S}, \mathrm{LU}$ \\
\hline MPI & mpi_echam5 & T63 L31 & 0.84 & SU & D, I1 & - \\
\hline MRI & mri_cgcm2 & T42 L30 & 0.86 & SU & $\mathrm{D}$ & $\mathrm{S}$ \\
\hline NCAR & ncar_ccsm3_0 & T85 L26 & 0.77 & SU, B\&OC & $\mathrm{D}, \mathrm{SV}$ & $\mathrm{V}, ?$ \\
\hline UKMO & ukmo_hadcm3 & $3.75^{\circ} * 2.5^{\circ} \mathrm{L} 19$ & $?$ & $?$ & $?$ & $?$ \\
\hline
\end{tabular}

Tab. 2

\begin{tabular}{|c|c|c|c|}
\hline \multicolumn{4}{|c|}{ Before VARIMAX } \\
\hline & SST-EC2 & GG index & Niño-3 index \\
\hline SST-EC1 & -0.48 & 0.10 & 0.95 \\
\hline SST-EC2 & & 0.74 & -0.51 \\
\hline GG index & & & -0.07 \\
\hline \multicolumn{4}{|c|}{ After VARIMAX } \\
\hline & SST-EC2 & GG index & Niño-3 index \\
\hline SST-EC1 & -0.28 & -0.02 & 0.93 \\
\hline SST-EC2 & & 0.90 & -0.25 \\
\hline GG index & & & -0.07 \\
\hline
\end{tabular}

Tab. 3

\begin{tabular}{|c|c|c|}
\hline & P-EC1 & SST-EC1 \\
\hline \multirow[t]{3}{*}{ Observations } & $5.8 \mathrm{y}$ & $5.2 \mathrm{y}$ \\
\hline & $3.6 \mathrm{y}$ & $3.6 \mathrm{y}$ \\
\hline & $2.2 \mathrm{y}$ & $2.3 \mathrm{y}$ \\
\hline \multirow[t]{3}{*}{ CSIRO } & $6.4 \mathrm{y}$ & \\
\hline & $4.7 \mathrm{y}$ & $5.5 \mathrm{y}$ \\
\hline & $3.2 \mathrm{y}$ & $3.2 \mathrm{y}$ \\
\hline \multirow[t]{5}{*}{ INM } & $7.9 \mathrm{y}$ & $6.8 y$ \\
\hline & $4.0 \mathrm{y}$ & $4.0 \mathrm{y}$ \\
\hline & $3.1 \mathrm{y}$ & $3.1 \mathrm{y}$ \\
\hline & & $2.7 \mathrm{y}$ \\
\hline & & $2.4 \mathrm{y}$ \\
\hline \multirow[t]{4}{*}{ MIROC } & $7.4 \mathrm{y}$ & $7.3 \mathrm{y}$ \\
\hline & $4.7 y$ & \\
\hline & $3.5 \mathrm{y}$ & $2.9 \mathrm{y}$ \\
\hline & & $2.2 \mathrm{y}$ \\
\hline \multirow[t]{4}{*}{ MRI } & $3.6 \mathrm{y}$ & $3.5 \mathrm{y}$ \\
\hline & $2.7 \mathrm{y}$ & $2.7 \mathrm{y}$ \\
\hline & $2.4 \mathrm{y}$ & $2.4 \mathrm{y}$ \\
\hline & $2.0 \mathrm{y}$ & $2.1 \mathrm{y}$ \\
\hline \multirow[t]{3}{*}{ UKMO } & $5.2 \mathrm{y}$ & $5.7 \mathrm{y}$ \\
\hline & $3.8 \mathrm{y}$ & $3.8 \mathrm{y}$ \\
\hline & & $2.6 \mathrm{y}$ \\
\hline
\end{tabular}


Tab. 4

\begin{tabular}{|c|c|c|c|}
\hline \multirow{5}{*}{ 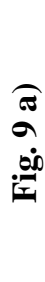 } & inm & $8.3 \notin[-13.8 ;-3.4]$ & \multirow{5}{*}{$\underline{5.1}$} \\
\hline & csiro & $\mathbf{1 1 . 1} \notin[-11.7 ; 6.3]$ & \\
\hline & miroc-1 & $2.5 \in[-22.3 ; 3.5]$ & \\
\hline & mri-1 & $9.8 \notin[-6.8 ;-2.9]$ & \\
\hline & ukmo & $\mathbf{- 4 . 1} \in[-19.2 ; 9.9]$ & \\
\hline \multirow{3}{*}{$\begin{array}{l}\text { a } \\
\text { a } \\
\text { 00 } \\
\text { 迋 }\end{array}$} & miroc-1 & $2.5 \in[-22.3 ; 3.5]$ & \multirow{3}{*}{$\underline{12.4}$} \\
\hline & miroc-2 & $24.1 \notin[-22.3 ; 3.5]$ & \\
\hline & miroc-3 & $\mathbf{1 0 . 7} \notin[-22.3 ; 3.5]$ & \\
\hline \multirow{3}{*}{ 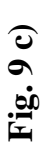 } & mri-1 & $9.8 \notin[-6.8 ;-2.9]$ & \multirow{3}{*}{$\underline{8.0}$} \\
\hline & mri-2 & $7.6 \notin[-6.8 ;-2.9]$ & \\
\hline & mri-3 & $6.4 \notin[-6.8 ;-2.9]$ & \\
\hline
\end{tabular}


Figures

Fig. 1
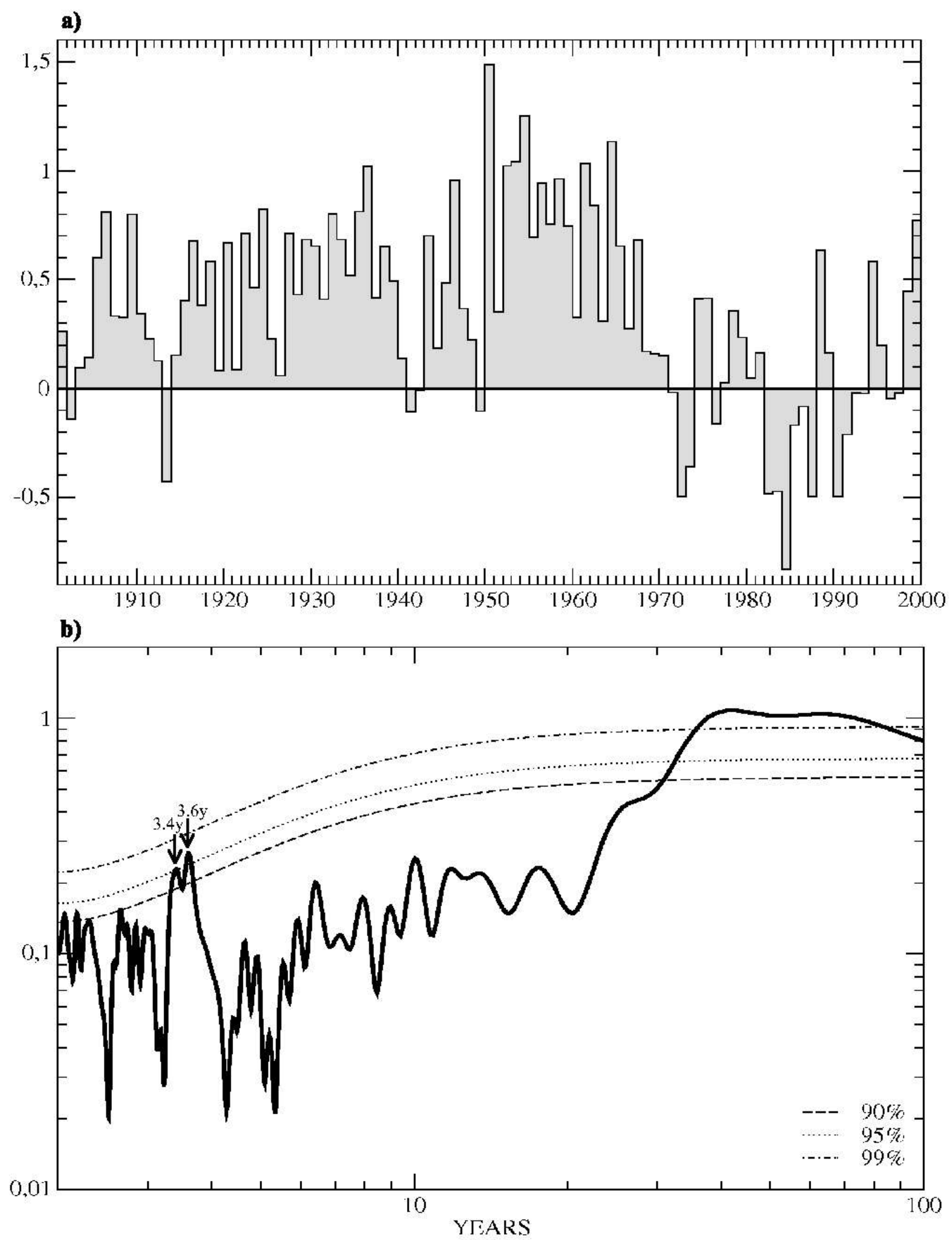
Fig. 2

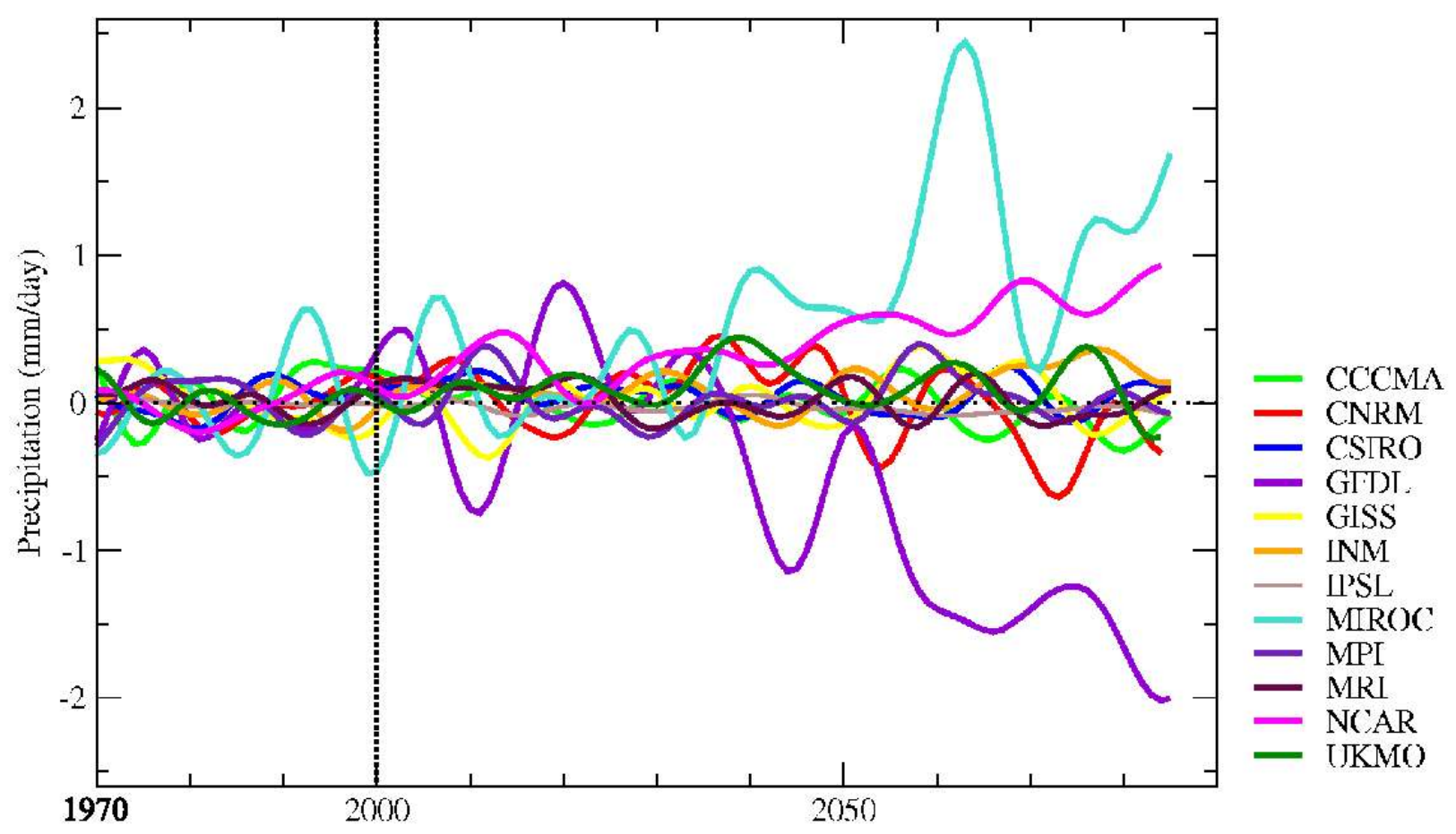

Fig. 3

a)

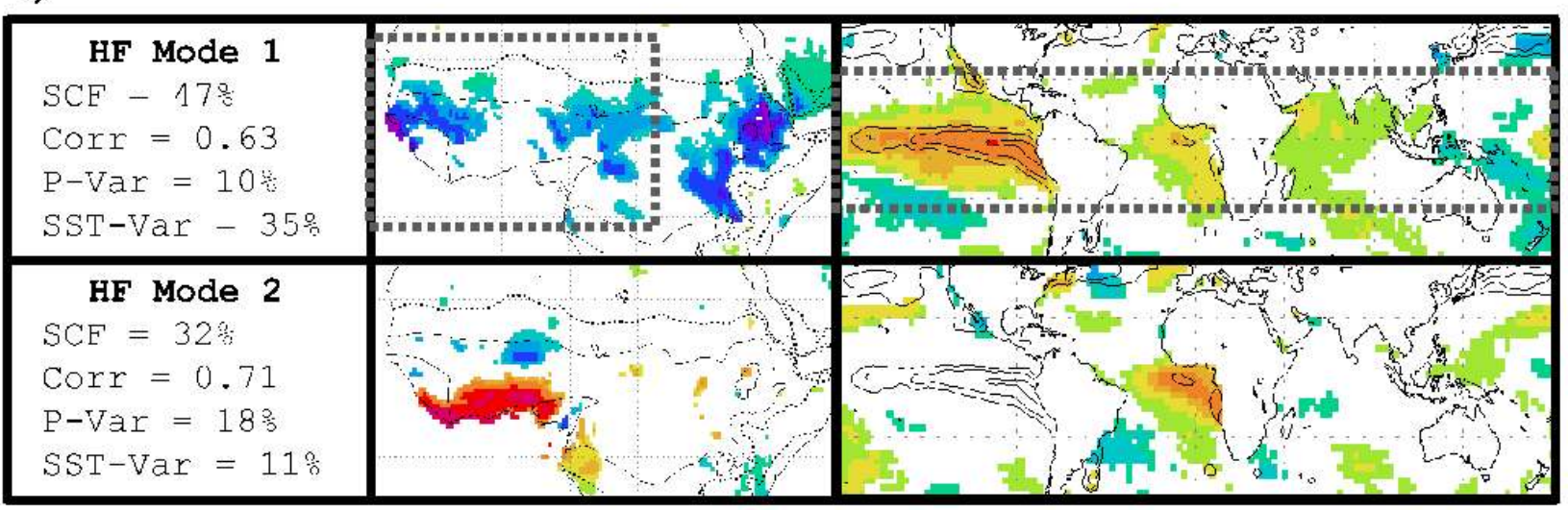

b)

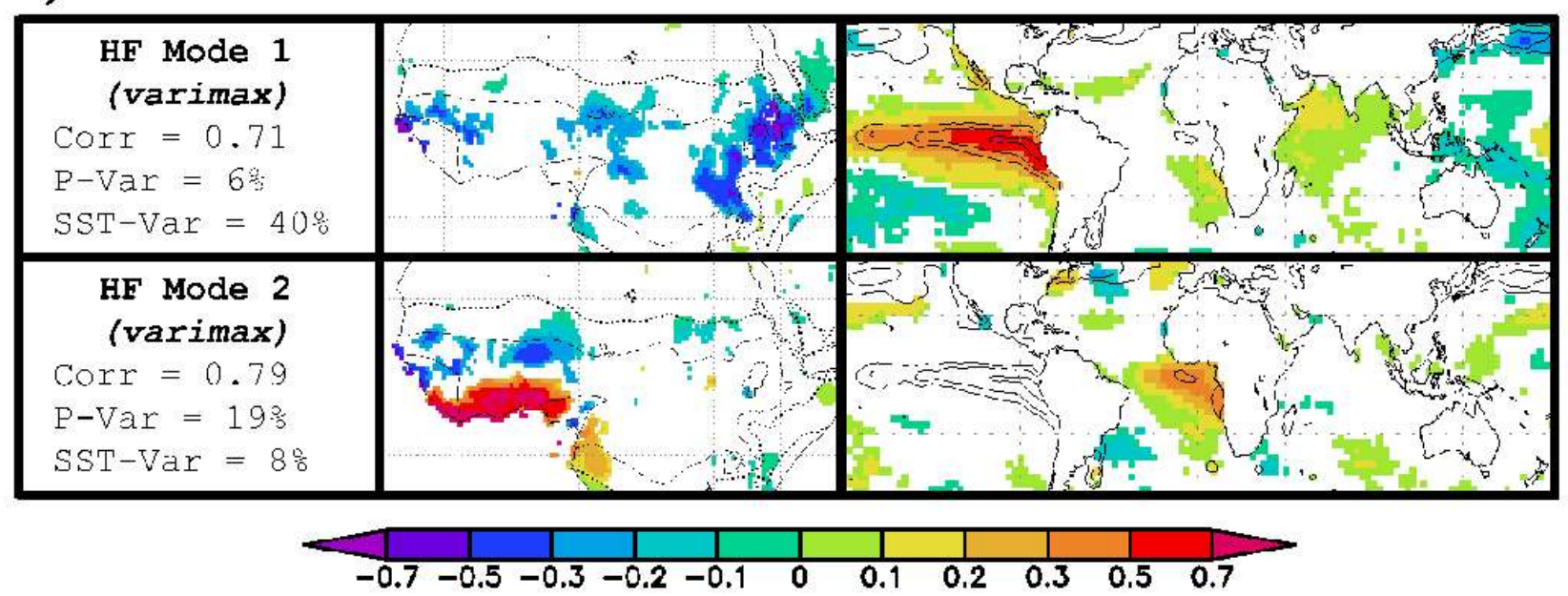


Fig. 4
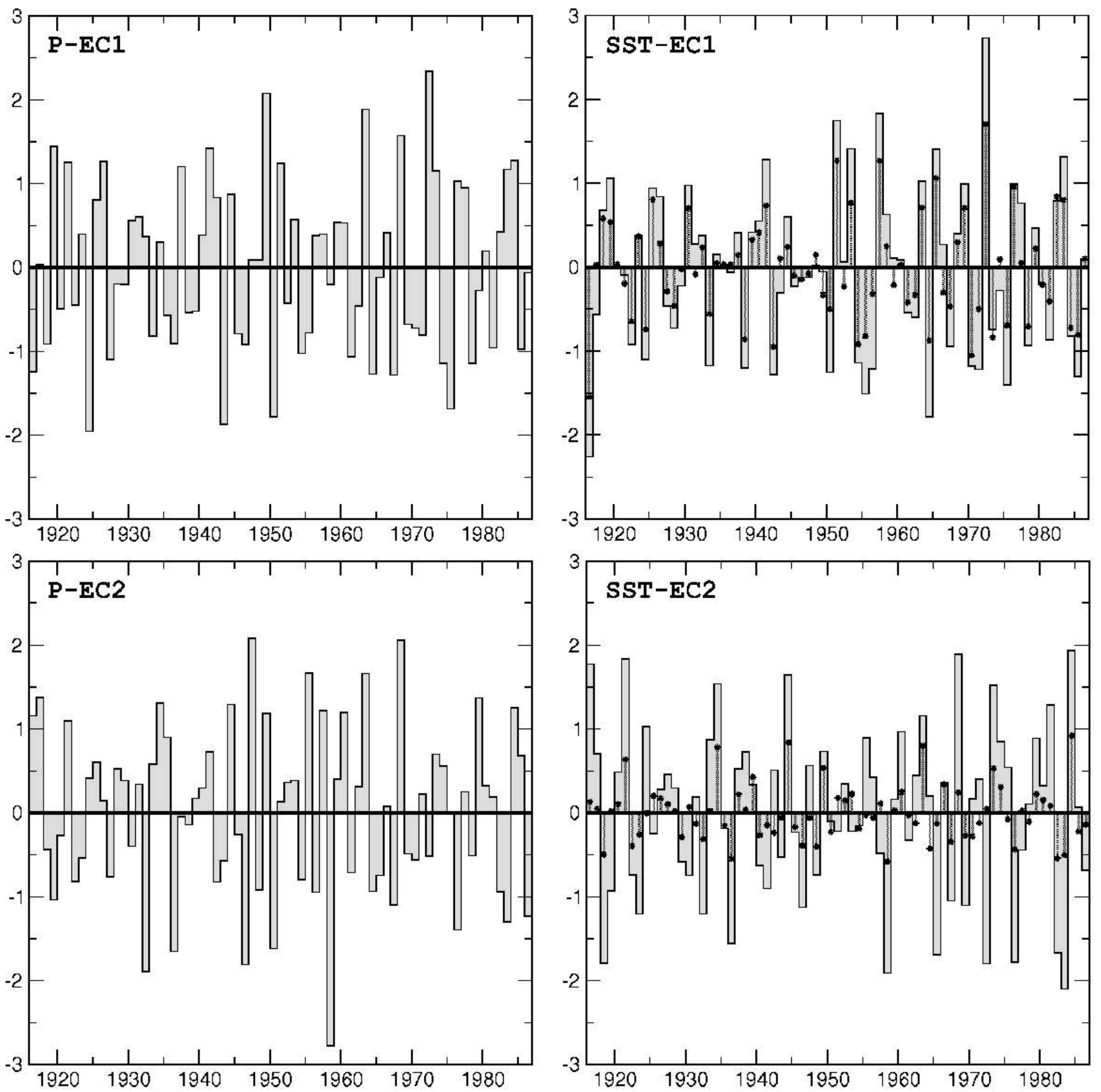

Fig. 5

\begin{tabular}{|c|c|c|c|}
\hline \multicolumn{4}{|c|}{ HF - MODE 1 } \\
\hline & SCF & P-var & SST-var \\
\hline OBS & 47 & 10 & 35 \\
\hline CCCMA & 40 & 26 & 7 \\
\hline CNRM & 87 & 25 & 36 \\
\hline CSIRO & $\mathbf{5 1}$ & 12 & 26 \\
\hline GFDL & $\mathbf{6 6}$ & 33 & 25 \\
\hline GISS & 70 & 52 & 6 \\
\hline INM & 88 & 39 & 43 \\
\hline IPSL & 90 & 38 & 32 \\
\hline MIROC & 73 & 25 & 26 \\
\hline MPI & 79 & 14 & 41 \\
\hline MRI & 87 & 22 & 39 \\
\hline NCAR & 64 & 11 & 34 \\
\hline UKMO & 69 & 18 & 33 \\
\hline
\end{tabular}

\begin{tabular}{|c|c|}
\hline \multicolumn{2}{|c|}{ Legend } \\
\hline SCF-signif & Va \\
\hline 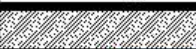 & $\geq 30 \%$ \\
\hline$\geq 90 \%$ & $\geq 15 \%$ \\
\hline$\geq 50 \%$ & $\geq 10 \%$ \\
\hline$\geq 10 \%$ & $\geq 5 \%$ \\
\hline$<10 \%$ & $<5 \%$ \\
\hline
\end{tabular}


Fig. 6

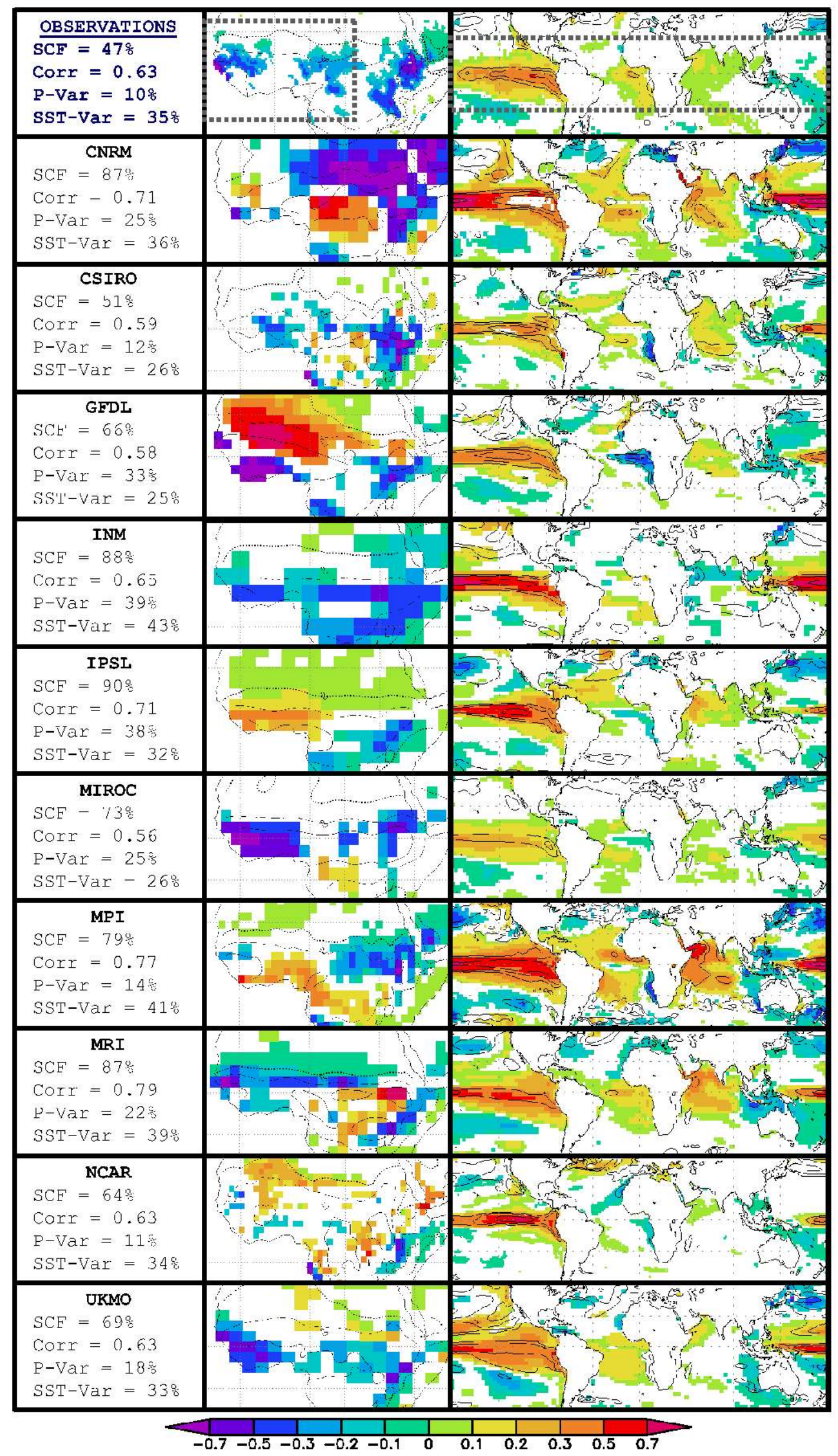


Fig. 7

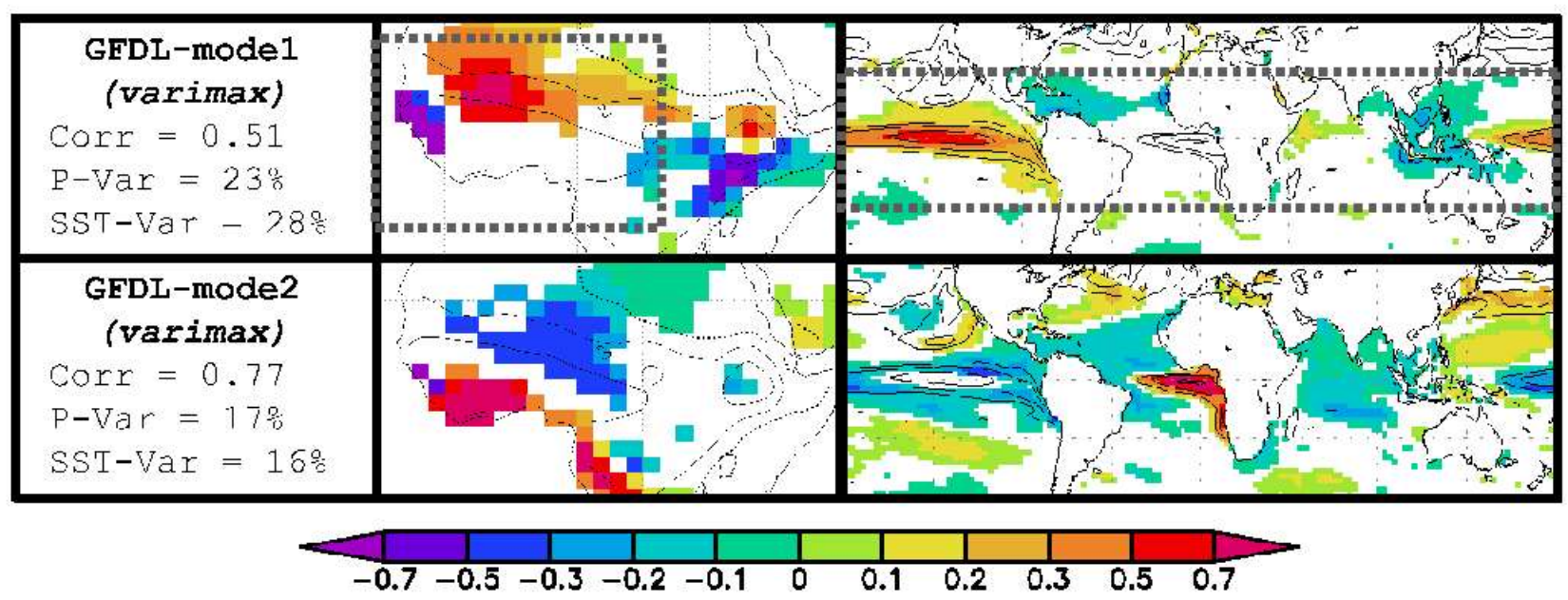

Fig. 8

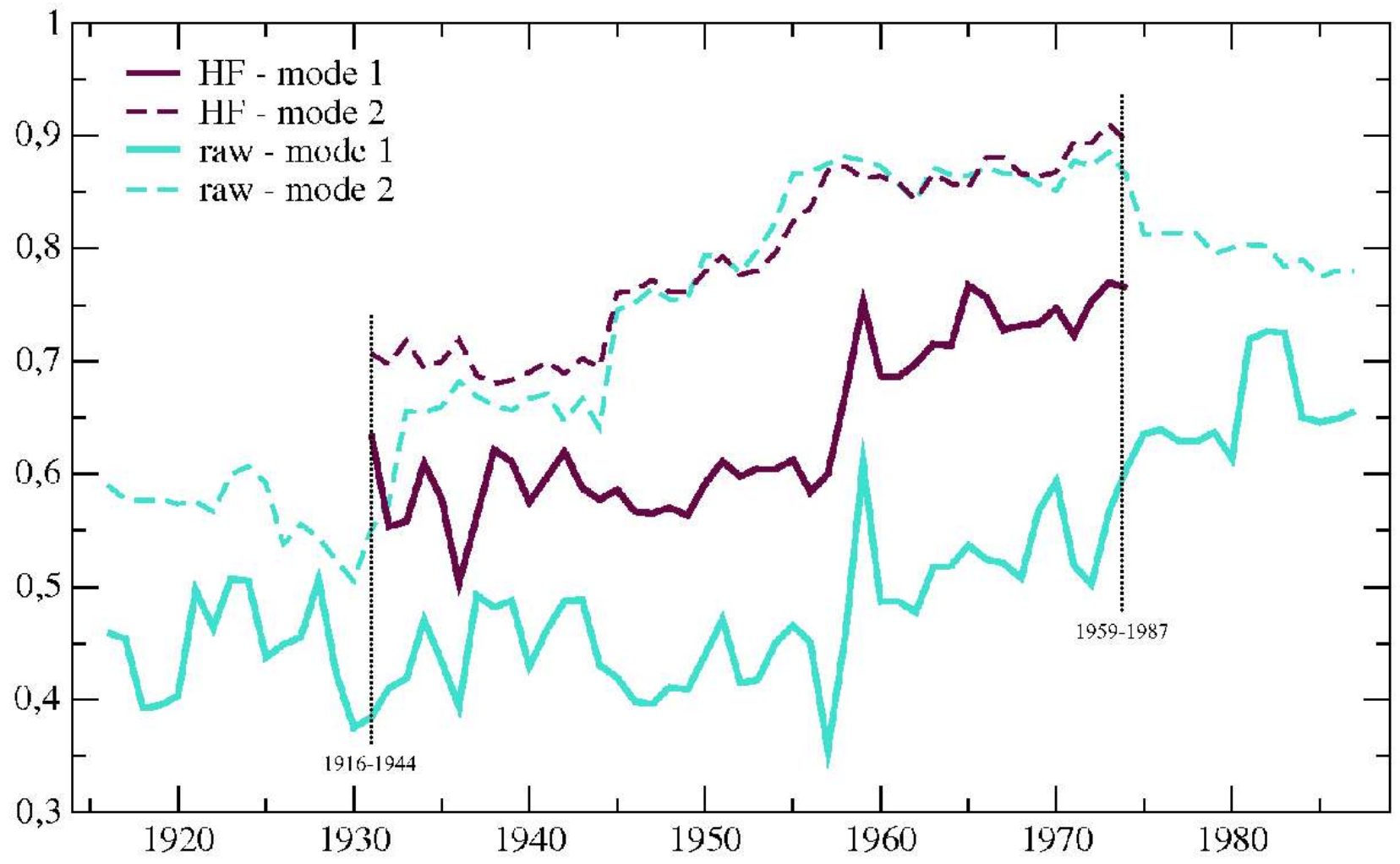


Fig. 9
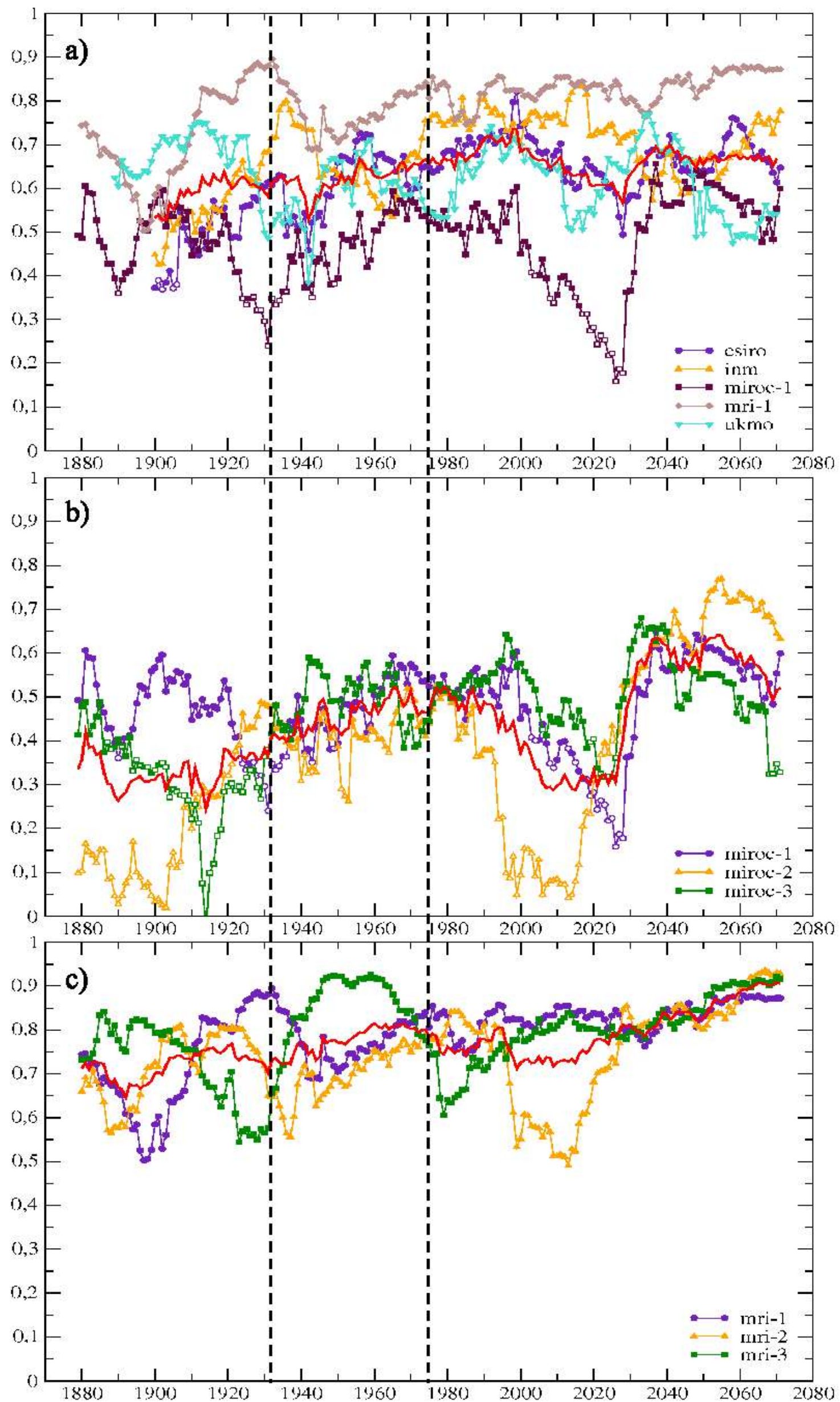
Fig. 10

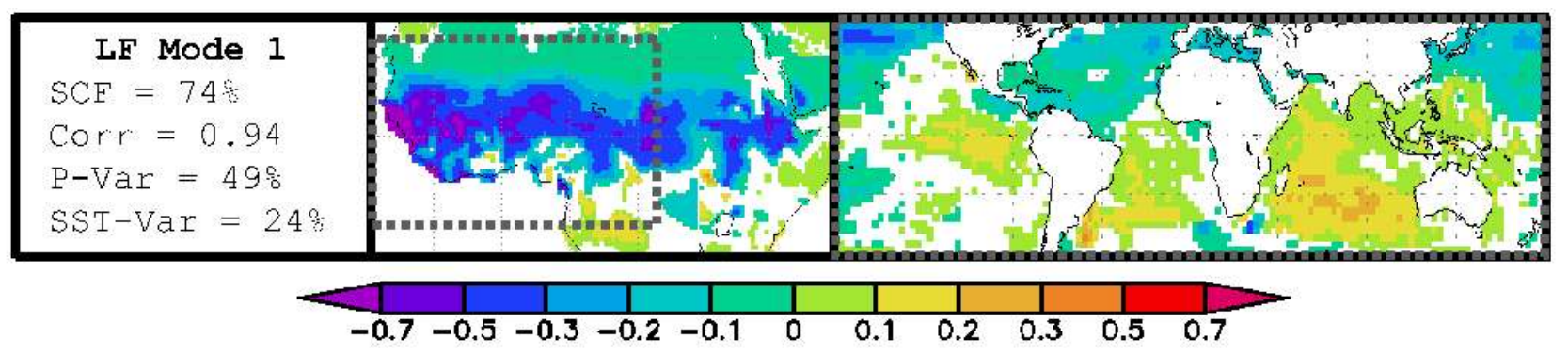

Fig. 11

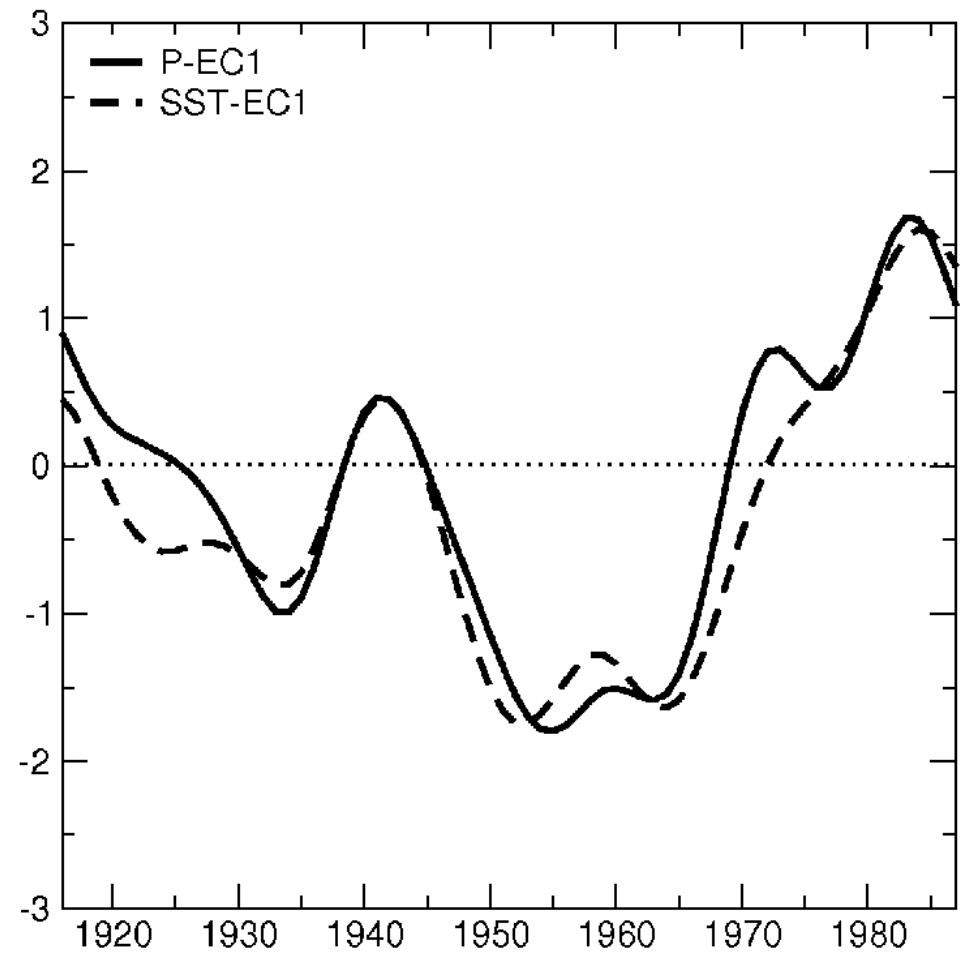

Fig. 12

\begin{tabular}{|c|c|c|c|}
\hline \multicolumn{4}{|c|}{ LF - MODE 1 } \\
\hline & SCF & P-var & SST-var \\
\hline OBS & 74 & 49 & 24 \\
\hline CCCMA & $\mathbf{2 4}$ & 20 & 7 \\
\hline CNRM & $\mathbf{4 8}$ & 33 & $\mathbf{9}$ \\
\hline CSIRO & $\mathbf{4 4}$ & 18 & $\mathbf{1 5}$ \\
\hline GFDL & $\mathbf{4 3}$ & $\mathbf{5 0}$ & $\mathbf{6}$ \\
\hline GISS & $\mathbf{5 2}$ & 44 & $\mathbf{6}$ \\
\hline INM & $\mathbf{4 3}$ & $\mathbf{2 4}$ & $\mathbf{1 7}$ \\
\hline IPSL & $\mathbf{5 7}$ & 34 & $\mathbf{1 6}$ \\
\hline MLROC & 71 & $\mathbf{5 0}$ & $\mathbf{1 8}$ \\
\hline MPI & 39 & 20 & $\mathbf{1 4}$ \\
\hline MRI & $\mathbf{6 5}$ & 25 & 21 \\
\hline NCAR & $\mathbf{3 9}$ & 27 & $\mathbf{1 3}$ \\
\hline UKMO & 71 & 26 & 24 \\
\hline
\end{tabular}


Fig. 13

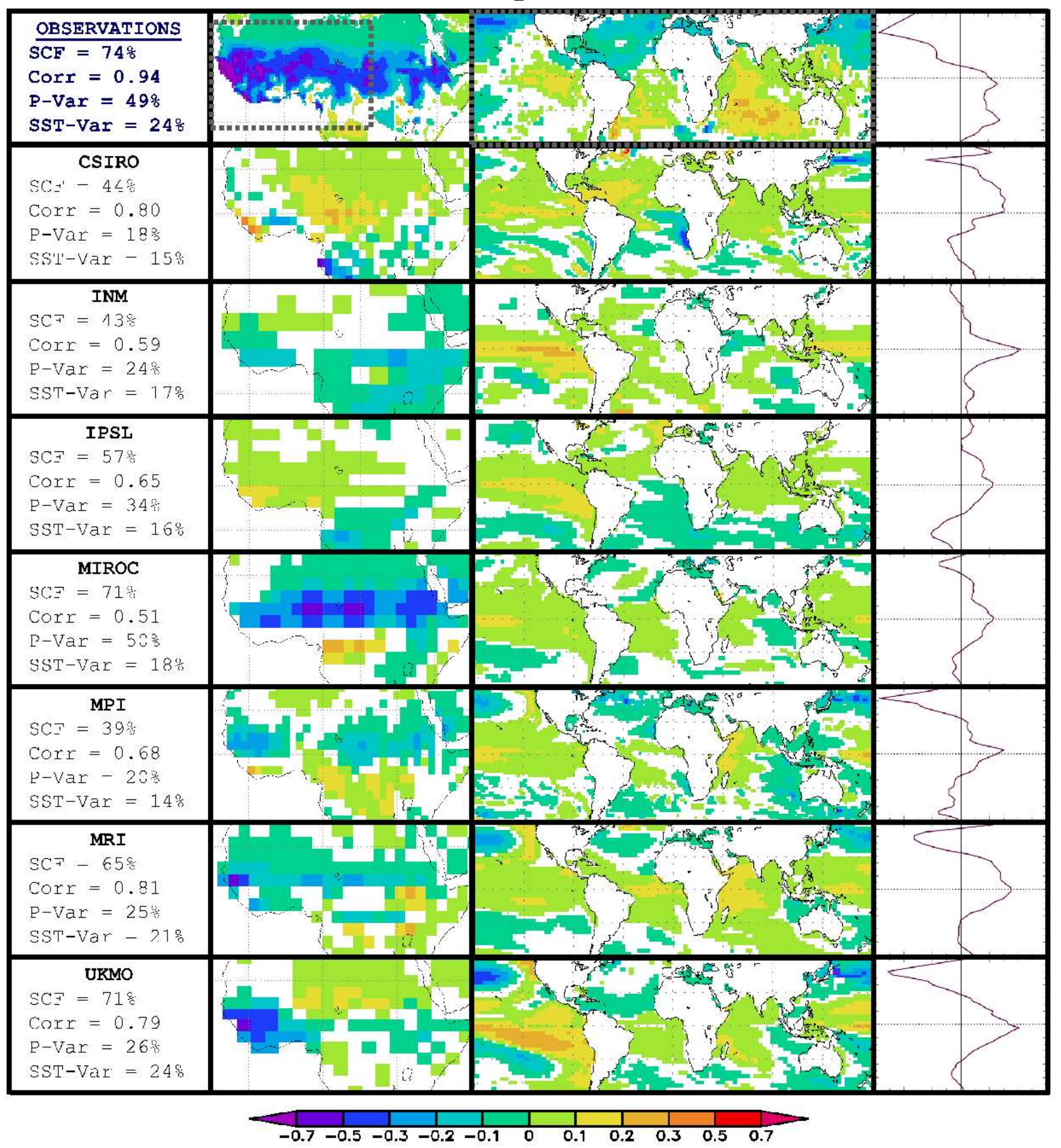


Fig. 14

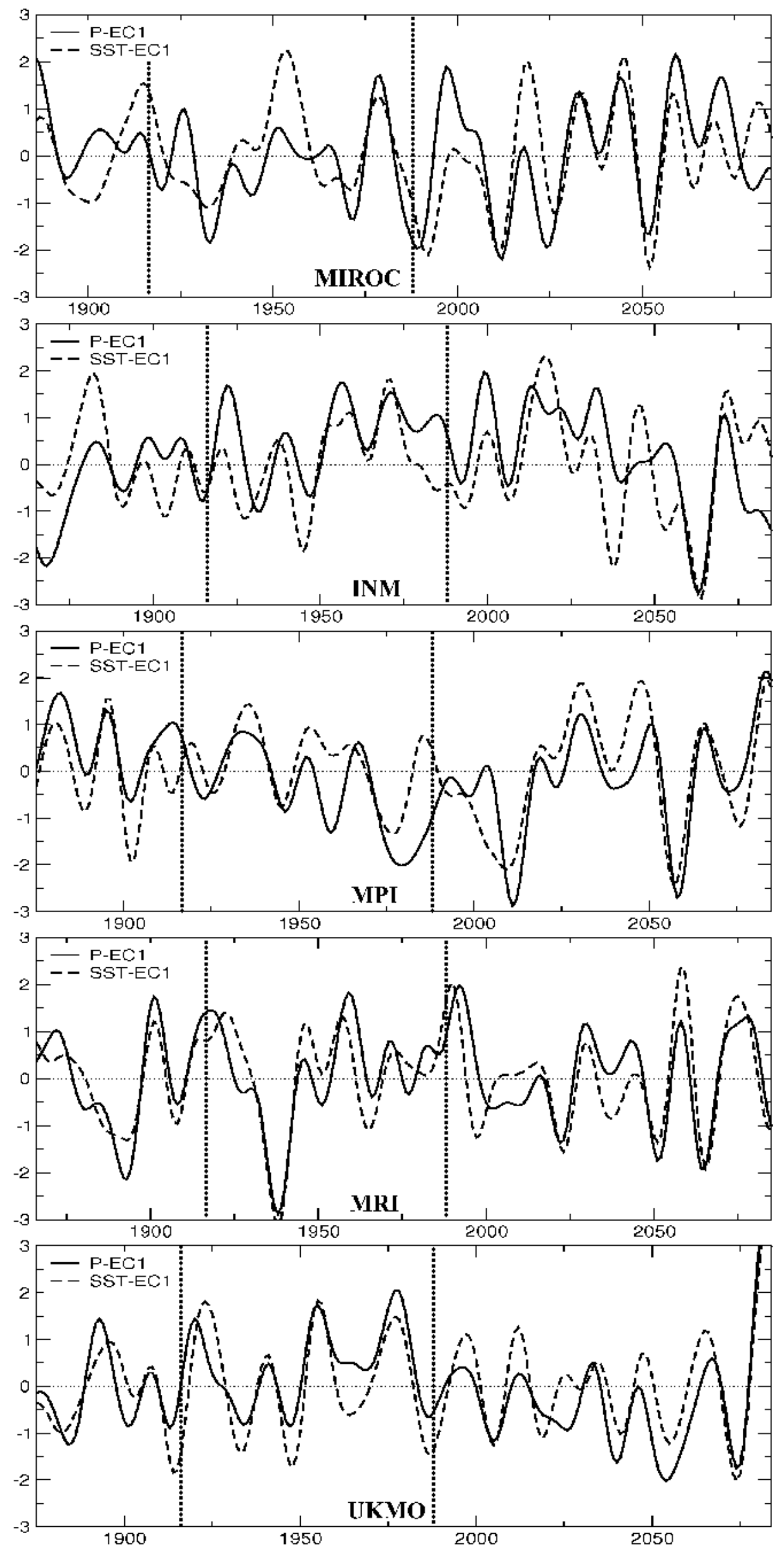

